
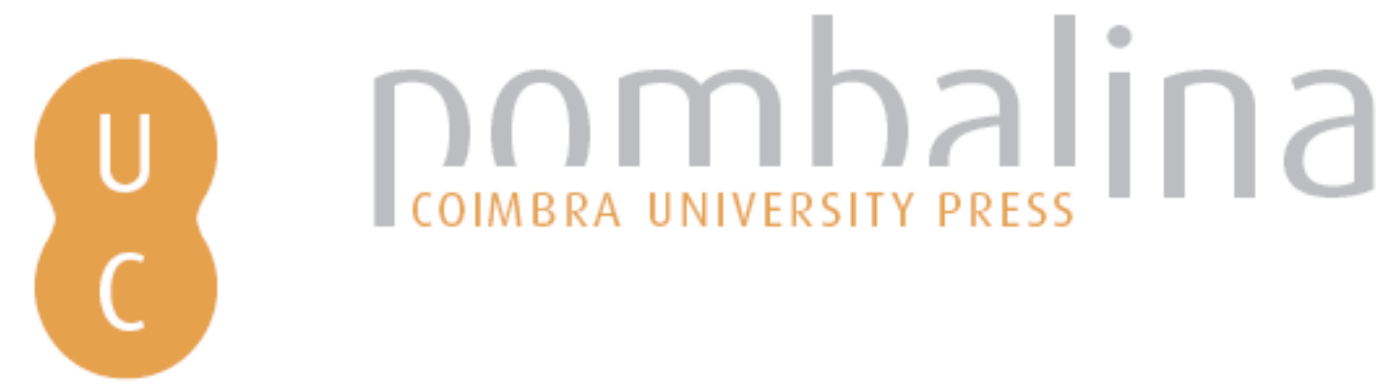

\title{
Estudos contemporâneos sobre Amato Lusitano
}

Autor(es): $\quad$ Pita, João Rui; Pereira, Ana Leonor

Publicado por: UA Editora - Universidade de Aveiro; Imprensa da Universidade de

URL

persistente: $\quad$ URI:http://hdl.handle.net/10316.2/35708

DOI: $\quad$ DOI:http://dx.doi.org/10.14195/978-989-26-0941-6_22

Accessed : $\quad$ 26-Apr-2023 08:52:12

A navegação consulta e descarregamento dos títulos inseridos nas Bibliotecas Digitais UC Digitalis, UC Pombalina e UC Impactum, pressupõem a aceitação plena e sem reservas dos Termos e Condições de Uso destas Bibliotecas Digitais, disponíveis em https://digitalis.uc.pt/pt-pt/termos.

Conforme exposto nos referidos Termos e Condições de Uso, o descarregamento de títulos de acesso restrito requer uma licença válida de autorização devendo o utilizador aceder ao(s) documento(s) a partir de um endereço de IP da instituição detentora da supramencionada licença.

Ao utilizador é apenas permitido o descarregamento para uso pessoal, pelo que o emprego do(s) título(s) descarregado(s) para outro fim, designadamente comercial, carece de autorização do respetivo autor ou editor da obra.

Na medida em que todas as obras da UC Digitalis se encontram protegidas pelo Código do Direito de Autor e Direitos Conexos e demais legislação aplicável, toda a cópia, parcial ou total, deste documento, nos casos em que é legalmente admitida, deverá conter ou fazer-se acompanhar por este aviso.

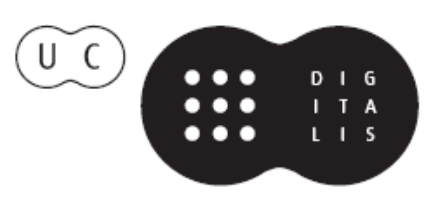




\section{HUMANISMO E CIÊNCIA Antiguidade e Renascimento}

António Manuel Lopes Andrade

Carlos de Miguel Mora

João Manuel Nunes Torrão
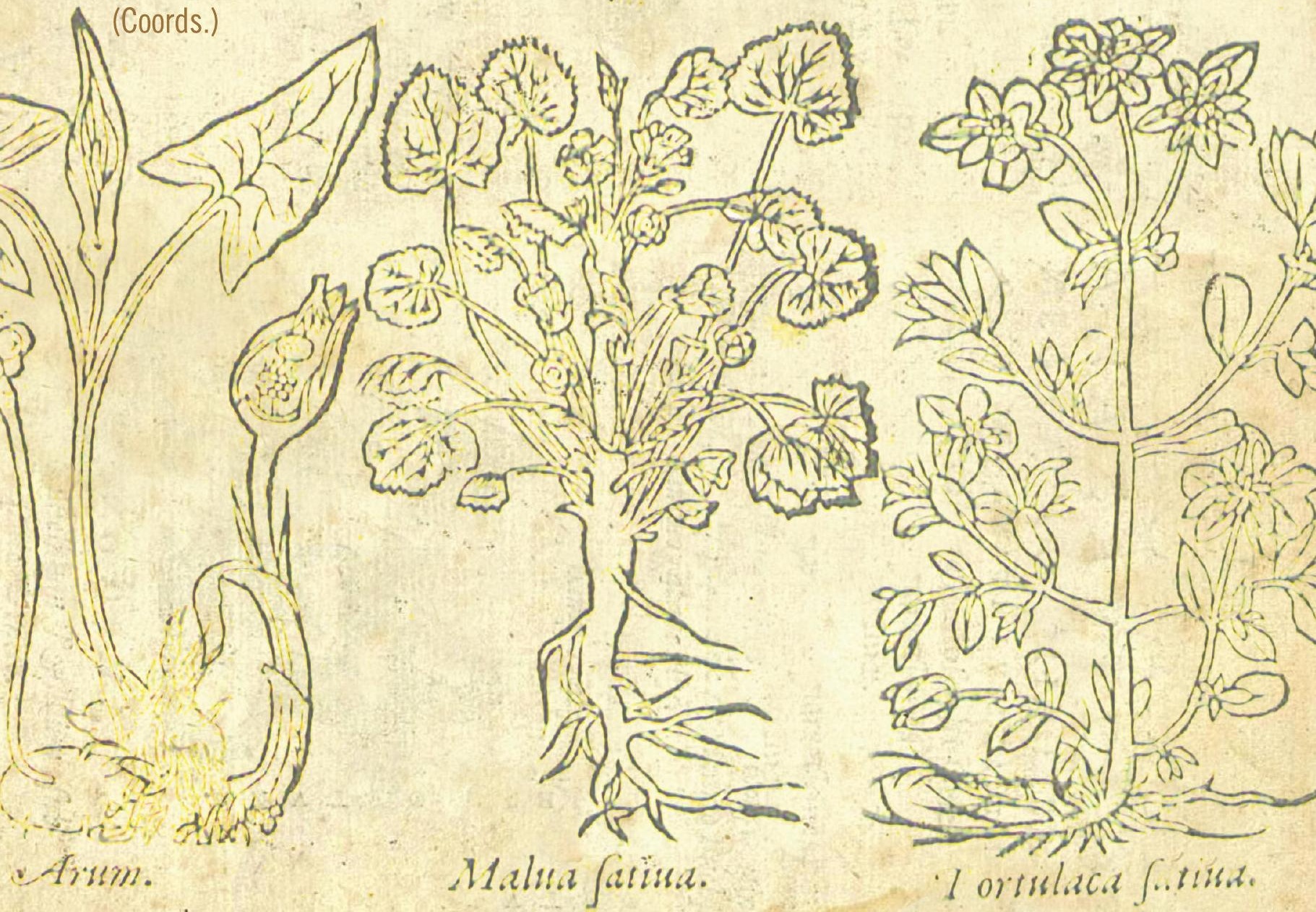

Aveiro I Coimbra I São Paulo 2015

UA Editora - Universidade de Aveiro I Imprensa da Universidade de Coimbra I Annablume 
Este volume resulta de várias iniciativas desenvolvidas no âmbito do projecto de I\&D "Dioscórides e o Humanismo Português: os Comentários de Amato Lusitano" (http://amatolusitano.web.ua.pt), recoIhendo contribuições de mais de duas dezenas de colaboradores, tanto de membros da equipa como de outros investigadores nacionais e estrangeiros. Entre os eventos que estiveram na origem deste livro destacam-se as três edições do Ciclo de Conferências promovido pelo projecto, realizadas entre 2010 e 2013, e sobretudo o Colóquio Internacional "Dioscórides e o Humanismo Português: os Comentários de Amato Lusitano", que decorreu no Departamento de Línguas e Culturas da Universidade de Aveiro, nos dias 21 e 22 de Novembro de 2013.

0 objectivo principal do projecto é a edição e tradução para português dos dois livros que Amato Lusitano dedicou ao comentário do tratado grego De materia medica de Dioscórides, ou seja, o Index Dioscoridis (Antuérpia, 1536) e as In Dioscoridlis Anazarbei de medica materia libros quinque... enarrationes (Veneza, 1553), estando contemplada, também, a tradução de mais duas obras directamente correlacionadas com os livros do médico português: a montante, a do próprio tratado grego de Dioscórides; a jusante, a do livro intitulado Apologia adversus Amathum Lusitanum (Veneza, 1558) de Pietro Andrea Mattioli.

OBRA PUBLICADA COM A COORDENAÇÃO

CIENTÍFICA DE:

Centro de Línguas, Literaturas e Culturas da Universidade de Aveiro

Centro de Estudos Clássicos e Humanísticos da Universidade de Coimbra

Cátedra de Estudos Sefarditas "Alberto

Benveniste" da Faculdade de Letras da Universidade de Lisboa 


\section{HUMANISMO E CIÊNCIA}

\section{Antiguidade e Renascimento}

ANTÓNIO MANUEL LOPES ANDRADE

CARLOS DE MIGUEL MORA

JOÃO MANUEL NUNES TORRÃO

(COORDS.)

AVEIRO • COIMBRA • SÃO PAULO

2015

UA EDITORA • UNIVERSIDADE DE AVEIRO

IMPRENSA DA UNIVERSIDADE DE COIMBRA

ANNABLUME 


\section{HUMANISMO E CIÊNCIA: Antiguidade e Renascimento}

\author{
EDIÇÃO

UA EDITORA • UNIVERSIDADE DE AVEIRO
IMPRENSA DA UNIVERSIDADE DE COIMBRA
ANNABLUME

ORGANIZAÇÃO E COORDENAÇÃO EDITORIAL ANTÓNIO MANUEL LOPES ANDRADE

CARLOS DE MIGUEL MORA

JOÃO MANUEL NUNES TORRÃO

\author{
DESIGN DA CAPA \\ MEIOKILO DESIGN STUDIO
}

DESIGN

CARLOS COSTA

IMPRESSÃO E ACABAMENTO

SERSILITO • MAIA

ISBN

UA • 978-972-789-434-5

IUC • 978-989-26-0940-9

\section{ISBN DIGITAL}

UA • 978-972-789-435-2

IUC • 978-989-26-0941-6

DOI

http://dx.doi.org/10.14195/ 978-989-26-0941-6

DEPÓSITO LEGAL 368241/13

TIRAGEM 500 Exemplares

(C) 2015

UA EDITORA • UNIVERSIDADE DE AVEIRO IMPRENSA DA UNIVERSIDADE DE COIMBRA

ANNABLUME

\section{COMISSÃO CIENTÍFICA}

António Manuel Lopes Andrade

Carlos de Miguel Mora

Delfim Ferreira Leão

Henrique Leitão

João Manuel Nunes Torrão

Maria de Fátima Reis

Maria do Céu Zambujo Fialho

Miguel Ángel González Manjarrés

\section{TEXTOS}

Adelino Cardoso

Ana Leonor Pereira

Ana Margarida Borges

António Guimarães Pinto

António Maria Martins Melo

Bernardo Mota

Carlos A. Martins de Jesus

Carlos de Miguel Mora

Cristina Santos Pinheiro

Donald Beecher

Emília Oliveira

Isabel Malaquias

James W. Nelson Novoa

Joana Mestre Costa

João Manuel Nunes Torrão

João Rui Pita

Jorge Paiva

José Sílvio Moreira Fernandes

Maria de Fátima Silva

Miguel Ángel González Manjarrés

Rui Manuel Loureiro

Telmo Corujo dos Reis

Teresa Nobre de Carvalho

Vinicije B. Lupis

Virgínia Soares Pereira 


\section{HUMANISMO E CIÊNCIA}

\section{Antiguidade e Renascimento}

ANTÓNIO MANUEL LOPES ANDRADE

CARLOS DE MIGUEL MORA

JOÃO MANUEL NUNES TORRÃO

(COORDS.)

AVEIRO • COIMBRA • SÃO PAULO

2015

UA EDITORA • UNIVERSIDADE DE AVEIRO

IMPRENSA DA UNIVERSIDADE DE COIMBRA

ANNABLUME 
OBRA PUBLICADA

COM A COORDENAÇÃO

CIENTÍFICA DE:

CENTRO DE LÍNGUAS,

LITERATURAS E CULTURAS DA

UNIVERSIDADE DE AVEIRO

CENTRO DE ESTUDOS

CLÁSSICOS E HUMANÍSTICOS DA

UNIVERSIDADE DE COIMBRA

CÁTEDRA DE ESTUDOS SEFARDITAS

"ALBERTO BENVENISTE"

DA FACULDADE DE LETRAS DA

UNIVERSIDADE DE LISBOA 


\section{SUMÁRIO}

PREFÁCIO

1.1 "Teofrasto, Tratado das plantas. No alvor de uma nova ciência" 13

Maria de Fátima Silva

1.2 "Francisco de Melo e os fragmentos de teoria óptica de Pierre Brissot" 21 Bernardo Mota

1.3 "Algumas reflexões sobre as pedras preciosas nos Colóquios dos simples de Garcia de Orta" 37 Rui Manuel Loureiro

1.4 "Estratégias, patronos e favores em Colóquios dos Simples de Garcia de Orta" 63 Teresa Nobre de Carvalho

1.5 "As plantas na obra poética de Camões (épica e lírica)" 95 Jorge Paiva

1.6 "Nicolás Monardes, John Frampton and the Medical Wonders of the New World" .141 Donald Beecher

1.7 "Literatura e Medicina: alguns textos de Justo Lípsio e de dois doutores Luís Nunes" 161 António Guimarães Pinto

1.8 "Ontologias e idiossincrasias dos Amantes, à luz da Archipathologia de Filipe Montalto" ...... 211 Joana Mestre Costa \& Adelino Cardoso

1.9 "Gabriel da Fonseca. A New Christian doctor in Bernini's Rome". .227 James W. Nelson Novoa 


\section{2) DIOSCÓRIDES E O HUMANISMO PORTUGUÊS: OS COMENTÁRIOS DE AMATO LUSITANO}

2.1 "Léxico científico português nos Comentários de Amato: antecedentes e receção"

Ana Margarida Borges

2.2 "Usos medicinais das plantas, em Amato Lusitano: o bálsamo"

António Maria Martins Melo

2.3 "Amato Lusitano e a importância da ilustração botânica no século xVI.

Em torno das edições lionesas das Enarrationes (1558)"

Carlos A. Martins de Jesus

2.4 "Sobre la identificación entre ébano y guayaco en una entrada

del Index Dioscoridis de Amato Lusitano".

Carlos de Miguel Mora

2.5 "Os partos distócicos em Amato Lusitano e em Rodrigo de Castro:

fontes, doutrinas e terapias greco-romanas"

\section{Cristina Santos Pinheiro}

2.6 "Do carvalho ao castanheiro: usos e propriedades medicinais

de fagáceas nas Enarrationes de Amato Lusitano".

Emília Oliveira

2.7 "O mundo mineral nos Comentários a Dioscórides de Amato Lusitano".

Isabel Malaquias \& Virgínia Soares Pereira

2.8 "Alguns comentários de Amato: entre a estranheza e a realidade"

João Manuel Nunes Torrão

2.9 "Caracterização e usos terapêuticos de produtos de origem marinha

nos Comentários de Amato Lusitano a Dioscórides"

José Sílvio Moreira Fernandes

2.10 "La mandrágora de Amato Lusitano: edición, traducción y anotación"

Miguel Ángel González Manjarrés

2.11 "O vinho e os vinhos - usos e virtudes de um dom dos deuses

nas Enarrationes de Amato Lusitano"

Telmo Corujo dos Reis

2.12 "Amatus Lusitanus e Didaco Pirro: due ebrei portoghesi

e cerchia umanistica di Dubrovnik" 481

Vinicije B. Lupis

2.13 "Estudos contemporâneos sobre Amato Lusitano". 513

João Rui Pita \& Ana Leonor Pereira 


\title{
Estudos contemporâneos sobre Amato Lusitano ${ }^{1}$
}

\author{
JOÃO RUI PITA² \& ANA LEONOR PEREIRA ${ }^{3}$
}

\section{RESUMO:}

Este estudo faz uma revisão dos artigos e livros publicados em Portugal sobre Amato Lusitano. Os autores, após analisarem as diferentes publicações, referem com particular destaque as obras resultantes de estudos de investigação mais profundos mas inscrevem igualmente estudos de natureza mais divulgativa sobre Amato Lusitano.

\section{PALAVRAS-CHAVE:}

Amato Lusitano; história da medicina; bibliografia; biografia

\section{ABSTRACT:}

This study is a literature review of articles and books published in Portugal on Amato Lusitano. The authors, after analyzing the different publications, refer specialized articles resulting from thorough research, as well as other studies for the diffusion of scientific knowledge about Amato Lusitano.

\section{KEYWORDS:}

Amato Lusitano; history of medicine; bibliography; biography

1 Este trabalho foi desenvolvido no âmbito do projecto de I\&D "Dioscórides e o Humanismo Português: os Comentários de Amato Lusitano" (http://amatolusitano.web.ua.pt) do Centro de Línguas, Literaturas e Culturas da Universidade de Aveiro, financiado por Fundos FEDER através do Programa Operacional Factores de Competitividade - COMPETE e por Fundos Nacionais através da FCT - Fundação para a Ciência e a Tecnologia, no âmbito do projecto FCOMP-01-0124-FEDER-009102.

2 Professor da Faculdade de Farmácia; Investigador do CEIS2O; Cocoordenador Científico do Grupo de História e Sociologia da Ciência e da Tecnologia - Universidade de Coimbra: jrpita@ci.uc.pt.

3 Professora da Faculdade de Letras; Investigadora do CEIS20; Cocoordenadora Científica do Grupo de História e Sociologia da Ciência e da Tecnologia)-Universidade de Coimbra: aleop@ci.uc.pt 
No presente estudo retomamos o trabalho que havia sido publicado em 2003 nos Cadernos de Cultura - Medicina na Beira Interior. Da Pré-História ao Século xxi ${ }^{4}$, estudo esse que havia sido actualizado em 2011 e publicado na mesma revista no ano de $2013^{5}$.

A publicação inicial resultou do projecto de investigação que realizámos há anos e que deu origem a uma linha de pesquisa do grupo de investigação que coordenamos, de História e Sociologia da Ciência e da Tecnologia do Centro de Estudos Interdisciplinares do Séc. xx da Universidade de Coimbra - CEIS20. O projecto intitula-se Repertório Bibliográfico da Historiografia Sanitária Portuguesa. Problemáticas e Fontes Especializadas / SANISTÓRIA (Sécs. XVIII-XX) (desenvolvido com financiamento da Fundação para a Ciência e a Tecnologia - FCT entre 1998 e 2000). A linha de investigação designa-se: "Fontes e bibliografia para a história da ciência em Portugal”. Somos os responsáveis científicos por essa linha cujo objectivo é: publicar e fazer publicar fontes impressas e manuscritas relacionadas, sobretudo, com a história das ciências da saúde e com a história das ciências exactas e naturais possibilitando dar a conhecer esses materiais com vista a investigações futuras. Constitui, também, objectivo desta linha-projecto publicar as investigaçôes sob a forma de repertórios bibliográficos, tanto repertórios gerais como bibliografias temáticas. Dada a natureza do objecto trata-se, então, de uma pesquisa permanente e continuada, sempre em actualização não só relativamente a Amato Lusitano mas também relativamente a outros vultos e temáticas da história das ciências, em particular da história das ciências da saúde e da vida.

O trabalho que agora se publica resulta pois da actualização contínua que temos realizado nesse projecto, neste caso especificamente sobre Amato Lusitano. Estamos conscientes de que é um trabalho inacabável.

Retomando o que foi publicado logo em 2003, sublinhamos que Amato Lusitano é uma das figuras mais relevantes da história da medicina portuguesa e, também, figura incontornável na história universal das ciências da saúde. As comemoraçóes dos 500 anos do nascimento de Amato Lusitano em que muitos investigadores estiveram envolvidos provam, justamente, essa universalidade e as marcas da sua acção clínica e científica. Estas marcas figuram em conceituados manuais de história da medicina e de história da farmácia para ficarmos apenas

4 João Rui PITA; Ana Leonor PEREIRA, "Escritos maiores e menores sobre Amato Lusitano", Medicina na Beira Interior. Da Pré-História ao Século xxı - Cadernos de Cultura 17 (2003), pp. 6-17. O estudo publicado em 2003 foi retomado, sujeito a actualizações e aumentado. Este estudo realiza-se no âmbito da linha de investigação do CEIS20 da Universidade de Coimbra, "Fontes e bibliografia para a história da ciência em Portugal" (FCT/ PEST-OE/HIS/UI0460/2014) e do projecto de investigação "Dioscórides e o Humanismo Português: os Comentários de Amato Lusitano" do Centro de Línguas, Literaturas e Culturas da Universidade de Aveiro, financiado por Fundos FEDER através do Programa Operacional Factores de Competitividade - COMPETE e por Fundos Nacionais através da FCT - Fundação para a Ciência e a Tecnologia, no âmbito do Projecto FCOMP-01-0124-FEDER-009102.

5 João Rui PITA; Ana Leonor PEREIRA, "História da história de Amato Lusitano", Medicina na Beira Interior. Da Pré-História ao Século xx। — Cadernos de Cultura 27 (2013), pp. 63-72. 
em estudos do domínio das ciências da saúde. Mas também poderíamos citar outras obras no campo das humanidades.

A obra de Amato Lusitano tem sido estudada por diversos investigadores dentro e fora do país. Das humanidades, no âmbito da cultura clássica, à história das ciências. As Jornadas de Estudo Medicina na Beira Interior, da Pré-História ao Século xxI, da responsabilidade máxima de António Lourenço Marques e de António Salvado, com a colaboração de Maria Adelaide Salvado, realizadas regularmente em Castelo Branco há duas décadas e meia, são uma prova de que a obra de Amato tem merecido e continua a exigir um estudo regular, envolvendo equipas multidisciplinares integrantes de historiadores da cultura, historiadores da ciência, antropólogos, linguistas, médicos, geógrafos, entre muitas áreas do conhecimento que poderiam ser referidas.

Merece também registo particular o projecto de investigação financiado pela Fundação para a Ciência e a Tecnologia - FCT, na Universidade de Aveiro, que se encontra em fase final. Este projecto de pesquisa tem como investigador responsável o Prof. Doutor António Andrade da referida Universidade de Aveiro. O projecto intitula-se Dioscórides e o Humanismo Português: os Comentários de Amato Lusitano. Trata-se de um programa de investigação pleno de originalidade e que envolve uma enorme quantidade de tradutores e especialistas de diversos domínios científicos, garantia do rigor científico necessário a investimentos dessa natureza e cujo objectivo é traduzir para português algumas das obras mais relevantes de Amato Lusitano. Sublinhese que, nos Cadernos de Cultura de 2010, António Andrade inscreve um artigo intitulado Projecto de Investigação "Dioscórides e o Humanismo Português: os Comentários de Amato Lusitano" onde aborda, justamente, os estudos a realizar e seu interesse ${ }^{6}$. Assinale-se que o projeto de investigação, de acordo com o responsável, "tem como objetivo principal a edição e tradução para português dos dois livros que Amato Lusitano dedicou ao comentário do tratado grego «De materia medica» de Dioscórides, ou seja, o «Index Dioscoridis» (Antuérpia, 1536) e as "In Dioscoridis Anazarbei de medica materia libros quinque...enarrationes» (Veneza, 1553)”. Ainda de acordo com o responsável do projecto, "está prevista, também, a tradução de mais duas obras diretamente correlacionadas com os livros do médico português: a montante, a do próprio tratado grego de Dioscórides sobre a matéria médica; a jusante, a do livro intitulado "Apologia adversus Amathum Lusitanum» (Veneza, 1558) da autoria do humanista Pietro Andrea Mattioli"8. Ainda decorrente deste projecto de pesquisa são de assinalar vários trabalhos intercalares publicados sob a forma de artigos e de livros?

6 António Manuel Lopes ANDRADE, "Projecto de Investigação Dioscórides e o Humanismo Português: os Comentários de Amato Lusitano", Medicina na Beira Interior. Da Pré-História ao séc. XXI - Cadernos de Cultura 23 (2010), pp. 5-9.

7 Cf. Site do projecto em: http://amatolusitano.web.ua.pt (consultado em 07/04/2014).

8 Idem.

9 Ver mais adiante a referência a vários destes estudos na revista Medicina na Beira Interior. Da Pré-História 
Deve também referir-se que a história da medicina portuguesa até meados do século xx não apresenta muitos vultos com projecção internacional, quer na dimensão clínica, quer na vertente científica. Em obras internacionais, raramente se encontra referência a outros nomes portugueses além de Amato Lusitano, de Garcia da Orta, de Ribeiro Sanches, de Bernardino António Gomes e de Egas Moniz, não havendo muitos mais, sendo muito curioso que praticamente todos tiveram profundas relaçóes com a Beira Interior. Amato era natural de Castelo Branco, Garcia da Orta nasceu em Castelo de Vide, Ribeiro Sanches era natural de Penamacor, Egas Moniz realizou praticamente todo o ensino secundário em Castelo Branco, no Colégio de São Fiel.

Pedro Laín Entralgo expóe na sua obra que, nos séculos XVI e XviI, vários médicos na Europa cultivaram uma nova vertente da literatura médica. Justamente uma vertente descritiva, clínica, protagonizada por grandes mestres com o objectivo de "transmitir aos outros o seu saber próprio"10. Laín salienta que entre os séculos XVI e XVII vários desses autores "cultivaram com brilhantismo esse novo género de literatura médica" ${ }^{11}$. Entre eles, o consagrado historiador espanhol cita o nome de Amato Lusitano ${ }^{12}$, sublinhando que todos os autores quinhentistas desse novo estilo de literatura médica tinham como denominador comum uma maior individualização, um tratamento biográfico na descrição das doenças e, para além disso, uma "intenção estética co-cognoscitiva"13. Conforme se lê textualmente, "mais do que a prescrição de um saber fazer" ${ }^{14}$, a observação do doente sensibiliza para um "saber ver"15 e um "saber entender"

ao séc. XXI - Cadernos de Cultura. De qualquer modo refira-se para já os estudos seguintes: o volume temático da revista Ágora. Estudos Clássicos em Debate 14.1 (2012). Número especial da revista decorrente da realização do Colóquio Internacional "Inventários, Livros e Ciência". Disponível em: http://www2. dlc.ua.pt/classicos/agora14.1.htm. A obra de António ANDRADE; João TORRÃo; Jorge COSTA; Júlio COSTA (org.), Humanismo, Diáspora e Ciência (séculos xVI e xVII): estudos, catálogo, exposição. Porto, Câmara Municipal do Porto, Biblioteca Pública Municipal; Universidade de Aveiro, Centro de Línguas e Culturas, 2013. Disponível em: http://arquivodigital.cm-porto.pt/Conteudos/Conteudos_BPMP/OBAD\%20 002710/0BAD\%20002710.htm (volume decorrente do Colóquio Internacional «Humanismo, Diáspora e Ciência» e da Exposição Bibliográfica, realizado na Biblioteca Pública Municipal do Porto, nos dias 7 e 8 de Março de 2013). A obra de António Guimarães PINTo, Apostilas a António Luís: 1. António Luís e João de Barros; 2. António Luís, António Pinheiro e Rodrigo Sánchez. Coordenação editorial e prefácio de Antonio Manuel Lopes Andrade. Lisboa - Aveiro, Cátedra de Estudos Sefarditas "Alberto Benveniste" da Universidade de Lisboa; Centro de Línguas e Culturas da Universidade de Aveiro, 2013 (volume editado numa colecção da Cátedra de Estudos Sefarditas "Alberto Benveniste" da Universidade de Lisboa, uma tradução de latim para português de vários textos de António Luís, um médico português do século xVI, colega de Amato Lusitano em Salamanca, realizada no âmbito do projeto por um membro da equipa).

10 Cf. Pedro Laín Entralgo, Historia de la medicina. Barcelona, Salvat, 1989, p. 312.

11 Cf. Idem, Ibidem, p. 313.

12 Ao lado de Amato Lusitano encontram-se os nomes de Jean Fernel, Giambatista da Monte, Francesco Valleriola, Peter van Foreest, Reiner Sondermann, Schenck von Grafenberg, Félix Platter, etc.

13 Cf. Pedro Laín Entralgo, Historia de la medicina, op. cit., p. 313.

14 Cf. Idem, Ibidem, p. 313.

15 Cf. Idem, Ibidem, p. 313.

16 Cf. Idem, Ibidem, p. 313. 
Muitos outros historiadores da medicina e da farmácia invocam ou referem a figura de Amato Lusitano, a sua vida e a sua obra. Tanto em tratados como em artigos científicos. É o caso, por exemplo, de M. Salomon ${ }^{17}$, Pietro Capparoni ${ }^{18}$, H. Friedenwald ${ }^{19}$, Glessinger ${ }^{20}$, Aldo Mieli $^{21}$, Samoggia ${ }^{22}$, Francisco Guerra ${ }^{23}$, de López Terrada, Salavert Fabiani ${ }^{24}$, Papaspyros ${ }^{25}$, Meunier $^{26}$, Leibowitz ${ }^{27}$, Hrvoje Tartalja ${ }^{28}$, Licurgo dos Santos Filho ${ }^{29}$, Jurica Bacic, Katarina Vilovic, Koraljka Bacic Baronica ${ }^{30}$, etc..

Vários dicionários contemplam a figura e a obra de Amato Lusitano. É o caso, por exemplo, do famoso Dicionário Biográfico de Cientistas, Dictionary of Scientific Biography ${ }^{31}$. Também em

17 Cf. M. Salomon, "Amatus Lusitanus in seine Zeit", Zeitschrift für klinische medizin 41-42 (1901).

18 Cf. Pietro Capparoni, "Amato Lusitano e la sua testimonianza della scoperta delle valvole delle vene fatta da G. B. Canano", in Atti e Memorie dell'Accademia di Storia dell'Arte Sanitaria, appendice alla Rassegna di Clinica, Terapia e Scienze affini, Anno XL, Fascicolo IV, Luglio-Agosto 1941.

19 Cf. H. Friedenwald, "Amatus Lusitanus", Bulletin of the Institute of History of Medicine, Johns Hopkins University 4 (1937).

20 Cf. Ladoslav Glassinger, Amatus Lusitanus. Zagreb-Belgrado, 1940.

21 Cf. Aldo Mielı, "Amatus Lusitanus", Archeion. Roma, 1910.

22 Cf. L. Samoggia, "Aspetti del pensiero scientifico di Amato Lusitano", Pagine di Storia della Medicina 10.3 (1966), p. 14.

23 Cf., por exemplo, Francisco Guerra, Historia de la medicina, vol. 1. Madrid, Ediciones Norma, S.A., 1989, p.294 e ss.; e 305 e ss.

24 Cf. María Luz López Terrada; Vicente L. Salavert Fabiani, "Le médecin de la Renaissance à l'aube des Lumières", in Louis CALLABERT (Dir.), Histoire du médecin. Paris, Flammarion, 1999, p. 143 e ss.

25 Cf. N. S. Papaspyros, The history of diabetes mellitus, $2^{\text {a }}$ ed.. Stuttgart, Georg Thieme Verlag, 1964. O autor refere que Amato teve declaradas preocupações com as causas de diabetes: excesso de comida, álcool e sexo (p. 15).

26 Cf. Meunier, Histoire de la médecine. Depuis ses origines jusqu'à nos jours. Paris, Librairie J.B. Baillière et Fils, 1911. Outra edição: Paris, Librarie E. le François, 1924. O autor faz uma breve súmula da vida de Amato, referindo-se a sua competência profissional, sobretudo em Ancona e refere a publicação das Centúrias (p. 216).

27 Cf., por exemplo, J. O. LeIBowitz, "A probable case of peptic ulcer described by Amatus Lusitanus", Journal of the History of Medicine and Allied Sciences 27 (1953), pp. 212-216; "Amatus Lusitanus and the Obturator in Cleft Palates", Bulletin of the History of Medicine 13 (1958), pp. 492-503.

28 Cf. Hrvoje TARTALja, "Les médicaments qu'Amatus Lusitanus utilisait à l'occasion de son travail à Dubrovnik", in F. J. Puerto SARMIEnto, Farmacia e industrializacion. Homenaje al doctor Guillermo Folch Jou. Madrid, Sociedad Española de Historia de la Farmacia, 1985, pp. 237-246.

29 Cf. Licurgo dos Santos FILHo, História Geral da Medicina Brasileira, vol. 1. São Paulo, Editora HUCITEC I Editora da Universidade de São Paulo, 1991. Diz o autor: "E João Rodrigues Castelo Branco (1511-1568), o celebrado 'Amato Lusitano', judeu português que estudou em Salamanca, clinicou em Castelo Branco e emigrou para Antuérpia, temeroso do Tribunal da Inquisição, reconheceu a púrpura e escreveu sobre as plantas medicinais das ilhas da Madeira e de São Tomé", p. 283.

30 Cf. Jurica BACIC; Katarina VILOVIC; Koraljka Bacic BARONICA, "The gynaecological-obstetrical pratice of the renaissance physician Amatus Lusitanus (Dubrovnik, 1555-1557)", European Journal of Obstetrics 8 Gynecology and Reproductive Biology 104.2 (2002), pp. 180-185.

31 Cf. A. G. Keller, "Lusitanus, amatus (RODRIGUes, JOÃO)", in Charles Gillispie Coulston (Ed.), Dictionary of Scientific Biography, vol. 8. New York, Charles Scribner's Sons, 1973, pp. 554-555. 
dicionários de judaísmo como a Encyclopedia Judaica ${ }^{32}$ o nome de Amato Lusitano é tratado. José Maria López Piñero na sua obra La medicina en la historia reporta-se a Amato Lusitano, valoriza a sua obra e atribui-lhe um lugar de relevo na medicina renascentista no que concerne à anatomia patológica ${ }^{33}$. López Piñero coloca Amato, nalgumas vertentes da sua actividade, a par de Mattiolo, Laguna, Vesálio, Fuchs, Monardes, etc. ${ }^{34}$.

Ugo Baldini, no volume primeiro da obra editada por Leen Spruit intitulada Catholic Church and Modern Science, publica o estudo "Amatus Lusitanus (João Rodriguez de Castelo Branco)" 35.

Por ocasião do quarto centenário do ano da morte de Amato (1568-1968), multiplicaram-se os eventos comemorativos, dentro e fora de Portugal. Vejamos alguns exemplos: na Academia das Ciências de Lisboa, a 25 de Abril de 1968, Maximino Correia e Miller Guerra recordaram Amato Lusitano; o primeiro teceu considerações biográficas e o segundo abordou a sua obra. Na Faculdade de Medicina da Universidade do Porto, Luís de Pina e Maria Olívia Rúber de Meneses, em 30 de Maio de 1968, evocaram nomes portuenses que estudaram a obra de Amato Lusitano. Em Siena, Itália, o xxi Congresso Internacional de História da Medicina, incorporou um simpósio subordinado ao tema "Amato Lusitano". O Simpósio congregou vários especialistas e interessados em Amato de diversos países europeus e de Israel. Em Castelo Branco o Liceu e a escola Comercial e Industrial organizaram sessóes públicas de homenagem a Amato. Destas comemorações resultou a publicação de obras marcantes no panorama historiográfico português e internacional. Saliente-se neste particular que, na obra $I V$ Centenário de João Rodrigues de Castelo Branco - Amato Lusitano, obra prefaciada e compilada por José Lopes Dias em 1968, “coligem-se em tomo independente os estudos de História da Medicina dos investigadores que dentro e fora do País participaram nas comemoraçóes quadricentenárias da morte de João Rodrigues de Castelo Branco — Amato Lusitano"36. Em 2011 tiveram lugar em Portugal as comemoraçóes do quinto centenário de Amato Lusitano. Em Castelo Branco o grupo promotor das Jornadas de Estudo Medicina na Beira Interior - Da Pré-História ao Século XxI organizou um evento comemorativo. Também em Castelo Branco tiveram lugar outras

32 Cf. Joshua O. Leibowitz, "Amatus Lusitanus (João Rodrigues de Castelo Branco", Encyclopedia Judaica, Vol. 2. Jerusalem, Keter Publishing House Ltd., 1971, pp. 795-797. Veja-se, também, por exemplo, "Amato Lusitano (Juan Rodrigo de Castelo Branco)", in Enciclopedia Judaica Castellana. México, Editorial Enciclopedia Judaica Castellana, S. de R. L., 1948, pp. 248-249.

33 Cf. José Maria López PIÑEro, La medicina en la historia. Madrid, La Esfera de los Libros, SL, 2002, pp. 207 e ss..

34 Cf. José Maria López PIÑERo, La medicina en la historia, op. cit., p. 232.

35 Cf. Ugo Baldini, "Amatus Lusitanus (João Rodriguez de Castelo Branco)", in Leen Spruit (ed.), Catholic Church and Modern Science. Documents from the Archives of the Roman Congregations of the Holy Office and the Index. Vol. 1 - 16th Century Documents. Roma, Libreria Editrice Vaticana, 2010. pp. 744-768.

36 Cf. IV Centenário de João Rodrigues de Castelo Branco - Amato Lusitano (Prefácio de José Lopes DIAS). Castelo Branco, Estudos de Castelo Branco, 1968, p. 7. 
manifestaçôes comemorativas ${ }^{37}$. Assinale-se, contudo, desde já as obras de J. David de Morais, Eu, Amato Lusitano. No V Centenário do seu Nascimento ${ }^{38}$ e Amato Lusitano, figura cimeira da Medicina portuguesa. No V Centenário do seu nascimento ${ }^{39}$.

De acordo com a nossa investigação em curso $^{40}$, entre estudiosos clássicos já desaparecidos, destacam-se três autores de escritos maiores sobre Amato Lusitano. São eles Maximiano Lemos, Ricardo Jorge e José Lopes Dias. Quanto às publicações periódicas que frequentemente abordam a obra de Amato destacam-se os Estudos de Castelo Branco e os actuais Cadernos de Cultura. Medicina na Beira Interior, da Pré-História ao Século xxi. Ambas as publicações, pelo conjunto e diversidade de artigos que reúnem constituem um valioso marco para a história de Amato Lusitano e indicam-nos os autores que hoje têm em Amato Lusitano um objecto de estudo. Na Biblioteca Nacional de Portugal, em Lisboa, teve lugar uma exposição e um seminário ${ }^{41}$, tendo sido editado igualmente um livro / catálogo da autoria de João José Alves Dias intitulado Amato Lusitano e a sua obra: séculos XVI e XVII ${ }^{42}$. O livro tem como objectivo dar a conhecer as obras "que são devidas a Amato Lusitano e que se publicaram durante pouco mais de um século em muitos prelos europeus” ${ }^{\prime 3}$.

\section{A BIOGRAFIA DE AMATO LUSITANO DA AUTORIA DE MAXIMIANO LEMOS}

Em 1907 Maximiano Lemos, professor de História da Medicina da Faculdade de Medicina da Universidade do Porto, publicou a obra Amato Lusitano que tem como sub-título A sua vida e a sua obra ${ }^{44}$. Trata-se de um grosso volume, cerca de 200 páginas, dividido em 12 capítulos e que na época recebeu o reconhecimento escrito por parte de outros investigadores, nomeadamente de Eduardo de Sousa no Diário da Tarde, de Sousa Viterbo em A Medicina Contemporânea e de Ricardo Jorge nos Arquivos da Medicina Portuguesa.

37 Ver mais adiante a propósito da revista Cadernos de Cultura.

38 J. David de Morals, Eu, Amato Lusitano. No V Centenário do seu Nascimento. Lisboa, Edições Colibri, 2011.

39 J. David de Morals, "Amato Lusitano, figura cimeira da Medicina portuguesa. No V Centenário do seu nascimento", Infecção e Sépsis 1 (2012), pp. 5-10.

40 Os resultados da nossa investigação aqui apresentados não pretendem ser um repertório completo da historiografia sobre Amato Lusitano.

41 Realizado em 13 de Setembro de 2011.

42 João José Alves DıAs, Amato Lusitano e a sua obra: séculos XVI e xVII. Lisboa, Biblioteca Nacional de Portugal: Centro Editor Livreiro da Ordem dos Médicos: Centro de Estudos Históricos-Univ. Nova, 2011. Trata-se de uma obra em 183 p.

43 Cf. http://livrariaonline.bnportugal.pt/Issue.aspx?i=2144 (consultado em 07/04/2014)

44 Maximiano Lemos, Amato Lusitano. A sua vida e a sua obra. Porto, Eduardo Tavares Martins, editor, 1907, $212 \mathrm{p}$. 
Maximiano Lemos traçou uma biografia cronológica de Amato no contexto familiar e no quadro da condição dos judeus em Portugal. O leitor acompanha a formação de Amato Lusitano em Salamanca, o exercício clínico de Amato em Portugal, a sua saída do país e o seu percurso pela Europa: Antuérpia, Ferrara, Veneza, Ancona, Roma, Florença, Pesaro, Salónica, etc. A obra apresenta, também, uma inventariação dos trabalhos de Amato Lusitano. Por tudo isto e ainda pela riqueza dos contextos culturais, religiosos, científicos e outros, este é, sem dúvida, um escrito maior sobre Amato Lusitano. Obviamente é um trabalho com a marca do tempo em que foi escrito e por isso mais importante ainda no domínio da história da história da medicina em Portugal que é precisamente o registo em que nos colocamos.

Maximiano Lemos publicou outros trabalhos de menor extensão sobre Amato Lusitano. O seu instinto de historiador dava-lhe a plena consciência de que as pesquisas não acabam com a obra feita. Elas continuam, trazem novidades e perturbam a história já contada e escrita. Maximiano Lemos confessa no artigo Amato Lusitano - Correç̧óes e aditamentos ${ }^{45}$ publicado em 1927 mas definitivamente redigido em 1922: "Muito há que ampliar, corrigir e modificar no que escrevemos há quinze anos acerca dos anos que Amato passou em Antuérpia"6. Entre outros textos de Maximiano Lemos sobre Amato assinalem-se: Amato Lusitano e as valvulas das veias $(1900)^{47}$, Medicos portuguezes no estrangeiro. Século XVI (1900) ${ }^{48}$, Amato Lusitano em Ferrara (1906) ${ }^{49}$ e Amato Lusitano (novas investigaçóes) (1915 e 1927) ${ }^{50}$. Posteriormente, a título póstumo (1955), foi recuperado o último capítulo da sua biografia de Amato para inclusão no volume intitulado Homenagem ao Doutor João Rodrigues de Castelo Branco (Amato Lusitano) publicado em $1955^{51}$. Hoje, cerca de cem anos volvidos, a biografia de Amato publicada em 1907 afirma-se como um documento fundamental para a história em todos os seus ramos, desde a história dos judeus à história da ciência, sendo igualmente um escrito maior para a história da história. Desde logo, a história da história de Amato.

45 Maximiano Lemos, "Amato Lusitano - Correcções e aditamentos", Revista da Universidade de Coimbra 10 (1927), pp. 1-38.

46 Idem, Ibidem, p. 5. No artigo fazem-se aditamentos e correcções a alguns dos capítulos da obra Amato Lusitano. A sua vida e a sua obra. Porto, Eduardo Tavares Martins, editor, 1907. Estão nesta situação aditamentos à presença de Amato em Antuérpia, em Ferrara e em Veneza.

47 Maximiano Lemos, "Amato Lusitano e as valvulas das veias", Gazeta Medica do Porto 4.2 (1900), pp. 37-41.

48 Maximiano Lemos, "Medicos portuguezes no estrangeiro. Século xVI", Gazeta Medica do Porto 3.7-8 (1900), pp. 198-205.

49 Maximiano Lemos, "Amato Lusitano em Ferrara", A Medicina Contemporânea 24.37 (1906), pp. 294-296; 24.38 (1906), pp. 299-301.

50 Maximiano Lemos, "Amato Lusitano (novas investigações)", Revista de Historia 2 (1913), pp. 25-31; "Amato Lusitano: novas investigações", Arquivos de História da Medicina Portuguesa. Nova série 6 (1915), pp. 1-12; 33-43; 89-96; 97-106; 129-145.

51 Maximiano Lemos, "Os trabalhos scientificos de Amato", in Homenagem ao Doutor João Rodrigues de Castelo Branco (Amato Lusitano). Castelo Branco, Câmara Municipal de Castelo Branco, 1955, pp. 37-56. 


\section{O AMATO LUSITANO DE RICARDO JORGE}

Ricardo Jorge é, também, um dos principais biógrafos de Amato Lusitano. Retrata-o muito justamente como "um caminheiro dominado pela paixão da ciência" ${ }^{2}$. Com o seu estilo inigualável, Ricardo Jorge converteu Amato num modelo para muitos cientistas e médicos, nomeadamente para o único Prémio Nobel de Medicina e Fisiologia português que foi Egas Moniz ${ }^{53}$.

Em 1914, Ricardo Jorge publica nos Arquivos de História da Medicina Portuguesa uma biografia de Amato intitulada Comentos à vida, obra e época de Amato Lusitano ${ }^{54}$, que vinha preparando desde 1907. Motivado pela biografia de Amato escrita por Maximiano Lemos, acabou por traçar um novo Amato Lusitano: "O que era a princípio um simples ensaio de apresentação crítica e levemente comentativa, foi-se adensando e dilatando" 55 . Os textos publicados por Ricardo Jorge nos Arquivos de História da Medicina Portuguesa correspondem essencialmente à vida de Amato em Portugal e em Espanha, digamos ao primeiro período da vida de João Rodrigues de Castelo Branco. Em A Medicina Contemporânea Ricardo Jorge publicou em 1908 Commentos á vida, obra e epocha de Amato Lusitano ${ }^{56}$.

Ricardo Jorge escrevia a propósito da publicação de um novo artigo intitulado Comentos à vida, obra e época de Amato Lusitano ${ }^{57}$ : "Maus fados de berço perseguiram o aparecimento deste trabalho, a testemunharem a adversão da publicidade que o meio reserva para certas obras e certos homens como que a condenar-lhes a pena à inércia e ao silêncio. Começado em Maio de 1907, foi tal a azáfama febril com que o acometi que, dentro de dois meses, tinha levado a carreira de Amato até à sua partida de Portugal. Continuado no ano seguinte, ficava o texto integralmente prontificado em meados de 1909"58. A publicação nos Arquivos de História da Medicina Portuguesa surgiu a convite de Maximiano Lemos. Aprontava-se uma edição total dos textos na Imprensa da Universidade de Coimbra, a convite do seu Director, Joaquim de Carvalho, em volume único, em 1933, quando esta instituição foi encerrada. Em 1936 publicou o referido

52 Ricardo JorGe, Amato Lusitano. Comentos à sua vida, obra e época. Lisboa, Edição do Centenário, 1963, p. 29.

53 Cf. Egas Moniz, Ao lado da medicina. Lisboa, Livraria Bertrand, 1940, p. 247.

54 Ricardo JorGe, "Commentos à vida, obra e época de Amato Lusitano", Arquivos de História da Medicina Portuguesa, Nova série 5 (1914), pp. 1-21; 97-119; 173-183; 6, 1915, pp. 161-175; 7, 1916, pp. 23-32; 47-57; 65-84. Ricardo JORG publicou em 1910 "Mestres d'Amato em Salamanca" em Archivos de Historia da Medicina Portugueza. Nova série 1.1 (1910), pp. 3-12. Veja-se, também, "Celestina (La) em Amato Lusitano", A Medicina Contemporânea 26.52 (1908), pp. 410-411.

55 Ricardo JORGE, "Comentos à vida, obra e época de Amato Lusitano (d'um Livro a publicar)", Arquivos de História da Medicina Portuguesa, Nova série 5 (1914), p. 8.

56 Ricardo JORGE,"Commentos á vida, obra e epocha de Amato Lusitano (d'um livro a publicar)", A Medicina Contemporânea 26.25 (1908), pp. 193-196.; 26.34 (1908), pp. 265-268.

57 Ricardo JORGE, "Comentos à vida, obra e época de Amato Lusitano", Clínica, Higiene e Hidrologia 2.9 (1936), pp. 331-337.

58 Idem, Ibidem. 
artigo Comentos à vida, obra e época de Amato Lusitano ${ }^{59}$, que o próprio autor considera como "a 2 a parte da obra que abrange o ciclo peninsular da vida e acçáo científica do Amato"60. Náo fora a intervenção directa do responsável da revista Dr. Armando Narciso e o artigo sobre a vida de Amato em Lisboa teria ficado apenas em manuscrito ${ }^{61}$. Em 1955, no volume intitulado Homenagem ao Doutor João Rodrigues de Castelo Branco (Amato Lusitano), editado pela Câmara Municipal de Castelo Branco, retoma-se, em capítulo autónomo, parte da escrita de Ricardo Jorge sobre Amato publicada nos Arquivos de História da Medicina Portuguesa $(1914)^{62}$.

A biografia de Amato feita por Ricardo Jorge só postumamente foi editada: Amato Lusitano. Comentos à sua vida, obra e época ${ }^{63}$, numa edição integrada na colecção comemorativa do centenário de Ricardo Jorge e intitulada "Obra Literária e Médico-Literária de Ricardo Jorge". Esta obra compila os artigos dispersos sobre Amato e inclui um capítulo mantido inédito até 1963, intitulado As conquistas e as drogas das Índias. Ricardo Jorge não terá tido tempo para redigir uma biobibliografia de Amato como parece ter sido sua ideia ${ }^{64}$.

As 200 páginas que Ricardo Jorge consagra a Amato ${ }^{65}$ incidem sobre a vida do médico de Castelo Branco até à sua saída para o estrangeiro, para terras de Antuérpia, Ferrara, Veneza, Roma, Salónica, etc. Para além duma nota editorial onde se referem as razóes da publicação, a obra abre com um prefácio intitulado "Carta ao prof. Maximiano de Lemos", documento já publicado nos Arquivos de História da Medicina Portuguesa (vol. 5, 1914, p. 1) e onde Ricardo Jorge, ao dirigir-se a Maximiano Lemos, justifica o seu interesse por Amato e a profunda motivação que recebeu com a leitura da biografia de Amato feita por Maximiano Lemos ${ }^{66}$. $\mathrm{Na}$ obra de Ricardo Jorge, Amato Lusitano também é integrado no contexto científico e cultural da época. Ambos compreenderam que biografar Amato implicava fazer uma viagem pelo

59 Idem, Ibidem.

60 Idem, Ibidem, p. 331.

61 Diz-nos Ricardo JorGE: "Há três anos, prestava-se bizarramente o dr. Joaquim de Carvalho à feitura duma edição total na Imprensa da Universidade que, para cúmulo de má sorte e dano irreparável das nossas letras, foi incontinenti fechada. A instâncias do redactor desta revista [Clínica, Higiene e Hidrologia] o dr. Armando Narciso, será agora arrancada ao esquecimento esta $2^{a}$ parte, depois de 26 anos de sono pesado nas gavetas" (Ricardo Jorge, "Comentos...", op. cit, p. 331).

62 Cf. Ricardo JorGe, "Comentos à vida, obra e época de Amato Lusitano", in Homenagem ao Doutor João Rodrigues de Castelo Branco (Amato Lusitano). Castelo Branco, Câmara Municipal de Castelo Branco, 1955, pp. 57-123.

63 Ricardo Jorge, Amato Lusitano. Comentos à sua vida, obra e época. Lisboa, Edição do Centenário, 1963.

64 Cf. O que nos diz a este propósito José Lopes DiAs em "João Rodrigues de Castelo Branco e a crítica histórica" in Homenagem ao Doutor João Rodrigues de Castelo Branco (Amato Lusitano). Castelo Branco, Câmara Municipal de Castelo Branco, 1955, p. 17.

65 A obra Amato Lusitano. Comentos à sua vida, obra e época. Lisboa, Edição do Centenário, 1963 tem um total de 278 páginas.

66 Referimo-nos a Maximiano Lemos, Amato Lusitano. A sua vida e a sua obra. Porto, Eduardo Tavares Martins, editor, 1907. 
Renascimento português e pela cultura e medicina do século xvi. São extremamente elucidativas as palavras de Américo da Costa Ramalho no artigo intitulado A propósito do Amato Lusitano de Ricardo Jorge ${ }^{67}$ onde, para além de pequenas notas relacionadas com algumas imprecisóes que deveriam ser entendidas "não como crítica, mas como homenagem à memória venerada de Ricardo Jorge" ${ }^{68}$ refere: “... apesar de constituído por elementos díspares e tâo afastados no tempo, o livro apresenta uma certa unidade e, o que é mais, a sua leitura depressa se torna um agradável prazer intelectual. Contribui para isso, não apenas a elegância da prosa de Ricardo Jorge, mas ainda o tom de amena narrativa, sempre reavivada por agudas observaçóes da vida e dos homens. E não lhe falta a nota cáustica de quem escreve para informar, e também para corrigir, no passado e no presente, os vezos dos seus compatriotas" ${ }^{69}$. Em 1963, no periódico Imprensa Médica publica-se um texto póstumo de Ricardo Jorge: um artigo intitulado Amato Lusitano $^{70}$ e que é, afinal, a introdução da obra do higienista publicada em 1963.

\section{JOSÉ LOPES DIAS — OUTRO BIÓGRAFO DE AMATO}

É extensa e valiosa a bibliografia sobre Amato Lusitano produzida por José Lopes Dias, compreendendo vários artigos dispersos em publicaçôes periódicas e algumas monografias. Refiram-se, por exemplo, os textos biográficos sobre Amato publicados no Jornal do Médico $(1943)^{71}$, na Revista Portuguesa de Medicina (1956) ${ }^{72}$, na Imprensa Médica (1961) ${ }^{73}$, em O Médico $(1965 ; 1969)^{74}$, no Colóquio (1969) $)^{75}$, em Estudos de Castelo Branco $(1970 ; 1971)^{76}$.

67 Cf. Américo da Costa Ramalho, "A propósito do 'Amato Lusitano' de Ricardo Jorge", Revista Portuguesa de História 10 (1962), pp. 501-508. Veja-se também em "A propósito do "Amato Lusitano" de Ricardo Jorge", in Estudos sobre a época do Renascimento. Coimbra, 1969, pp. 187-195.

68 Américo da Costa Ramalho, "A propósito...", op. cit., p. 501.

69 Cf. Américo da Costa Ramalho, "A propósito...", op. cit., p. 501.

70 Ricardo Jorge, "Amato Lusitano", Imprensa Médica 28.2 (1963), pp. 58-68.

71 Cf. José Lopes Dias, "Amato Lusitano", Jornal do Médico 3.66 (1943), pp. 417-418.

72 Cf. José Lopes DiAs, "[Amato Lusitano]", Revista Portuguesa de Medicina 5.6 (1956), pp. 178-181.

73 Cf. José Lopes DiAs, "Laços familiares de Amato Lusitano e Filipe Montalto (novas investigações)", Imprensa Médica 25.1 (1961), pp. 22-36; 25.2 (1961), pp. 53-69.

74 Cf. José Lopes Dias, "Doutor João Rodrigues de Castelo Branco (Amato Lusitano)", O Médico, Nova série. 35.721 (1965), p. 947; "IV Centenário de João Rodrigues de Castelo Branco", O Médico, Nova série. 50.916 (1969), pp. 1213-1214.

75 Cf. José Lopes Dias, "Pró-memória do Dr. João Rodrigues de Castelo Branco — Amato Lusitano (1511— 1568)", Colóquio 2 (1969), pp. 58-63.

76 Cf. José Lopes Dias, "João Roiz de Castell Branco — Poeta do "Cancioneiro Geral" de Garcia de Rezende, e João Rodrigues de Castelo Branco, Amato Lusitano - Insigne Médico do Séc. xvı", Estudos de Castelo Branco 34 (1970), pp. 5-18; "Biografia de Amato Lusitano e outros ensaios amatianos", Estudos de Castelo Branco 37 (1971), pp. 3-234. 
Outros estudos versando questóes anatómicas, clínicas e terapêuticas na obra de Amato foram publicados por José Lopes Dias. Por exemplo: o problema das válvulas das veias ${ }^{77}$; questões gerais de terapêutica (Imprensa Médica, 1945) ${ }^{78}$; a sífilis (Arquivos do Instituto de Farmacologia e Terapêutica Experimental, 1944-45)79; casos clínicos (Jornal da Sociedade das Ciências Médicas de Lisboa, 1969; Semana Médica, 1969) ${ }^{80}$.

José Lopes Dias também se dedicou aos estudos sobre Amato Lusitano, dando, assim, um contributo para a história da história de Amato Lusitano. Assinalem-se, por exemplo, os trabalhos: Ensaio do Dr. J. O. Leibowitz sobre Amato Lusitano (Imprensa Médica, 1952) ${ }^{81}$; João Rodrigues de Castelo Branco e a crítica histórica (1955) ${ }^{82}$; a polémica mantida com Abílio Mendes a propósito de Amato, publicada em O Médico e Estudos de Castelo Branco ${ }^{83}$. Refira-se também o seu trabalho sobre o texto do humanista Ambrósio Nicandro publicado em Estudos de Castelo Branco $(1968)^{84}$.

José Lopes Dias legou-nos outros estudos fundamentais: O Renascimento em Amato Lusitano e Garcia d'Orta (Estudos de Castelo Branco, 1964)"85; os Comentários ao "Index Dioscoridis"

77 Cf. José Lopes DiAs, "Nota especial sobre a descoberta das válvulas das veias na cátedra de anatomia de Ferrara, durante o ano de 1547" in Homenagem ao Doutor João Rodrigues de Castelo Branco (Amato Lusitano). Castelo Branco, Câmara Municipal de Castelo Branco, 1955, pp. 125-136.

78 Cf. José Lopes Dias, "Terapêutica de Amato Lusitano", Imprensa Médica 11.4 (1945), pp. 54-56; 11.6 (1945), pp. 84-88; 12.3 (1946), pp. 36-42; 12.4 (1946), pp. 53-58.

79 Cf. José Lopes DIAS, "Terapêutica da sífilis em Amato Lusitano", Arquivos do Instituto de Farmacologia e Terapêutica Experimental 8 (1944-1945), pp. 7-36.

80 Cf. José Lopes DiAs, "Apontamento breve sobre Amato Lusitano (casos clínicos de Portugal e dos portugueses)", Jornal da Sociedade das Ciências Médicas de Lisboa 133.6 (1969), pp. 495-505; José Lopes DIAS, "Apontamentos sobre Amato Lusitano (casos clínicos de Portugal e dos portugueses)", Semana Médica 11:512 suplemento (1969), pp. 1-3.

81 Cf. José Lopes DiAs, "Ensaio do Dr. J. O. Leibowitz sobre Amato Lusitano", Imprensa Médica 16.10 (1952), pp. 495-502.

82 Cf. José Lopes DiAs, "João Rodrigues de Castelo Branco e a crítica histórica" in Homenagem ao Doutor João Rodrigues de Castelo Branco (Amato Lusitano). Castelo Branco, Câmara Municipal de Castelo Branco, 1955, pp. 7-36. Este trabalho foi retomado e alterado nalgumas partes e novamente publicado com o título "Biógrafos, críticos e adversários de Amato Lusitano". Cf. José Lopes DIAS, "Biografia de Amato Lusitano e outros ensaios amatianos", Estudos de Castelo Branco 37 (1971), pp. 3-234.

83 Cf. José Lopes DiAs, "Doutor João Rodrigues de Castelo Branco (Amato Lusitano) [artigo de polémica com Abílio T. Mendes]", O Médico, Nova série, 36.724 (1965), pp. 150-155; "Um desafinado dueto de médicos, sobre Amato Lusitano", Estudos de Castelo Branco 19 (1966), pp. 106-126.

84 Cf. José Lopes DiAs, "Elogio de Amato Lusitano pelo humanista Ambrósio Nicandro", Estudos de Castelo Branco 26 (1968), pp. 164-171.

85 José Lopes DiAs, "O Renascimento em Amato Lusitano e Garcia d'Orta", Estudos de Castelo Branco 11 (1964), pp. 5-34.

86 José Lopes DiAs, Comentários ao "Index Dioscoridis" de Amato Lusitano. Castelo Branco, Gráfica S. José, 1968, 28 p.; "Comentários ao "Index Dioscorides" de Amato Lusitano", Centenário (IV) de João Rodrigues de Castelo Branco - Amato Lusitano. Castelo Branco, Estudos de Castelo Branco, 1968, pp. 87-109; "Comentários ao 'Index Dioscoridis' de Amato Lusitano", Estudos de Castelo Branco 28 (1968), pp. 135-157; "O Index Dioscoridis de Amato Lusitano", Semana Médica 11.521 (1969), 
O clima de Lisboa, de Castelo Branco e da Guarda, segundo os comentários de Amato Lusitano $(1968)^{87}$ e outros textos ${ }^{88}$.

A iconografia amatiana também foi objecto de estudo de José Lopes Dias que publicou sobre esta matéria ${ }^{89}$, para além de vários textos alusivos às comemorações do IV Centenário de Amato $^{90}$. Ficaria incompleta esta abordagem sumária da bibliografia de José Lopes Dias sobre Amato se não referíssemos os textos de prefácio à publicação das Centúrias de Amato, publicados em colaboração com Firmino Crespo ${ }^{91}$.

No conjunto da obra de José Lopes Dias sobressai o grosso volume de textos dispersos, publicado em 1971 como número autónomo da revista Estudos de Castelo Branco, intitulado Biografia de Amato Lusitano e outros ensaios amatianos ${ }^{92}$ e, ainda, Amato Lusitano. Doutor Joáo Rodrigues de Castelo Branco. Ensaio biobibliográfico publicado em $1941^{93}$, trabalho que aborda as relaçôes iniciais de Amato com Portugal, acompanha o percurso de Amato de Portugal para Espanha e depois a saída de Portugal para Antuérpia, Ferrara, Ancona, Roma, Ragusa e Salónica, incide sobre a actividade científica de Amato e ainda se dedica ao tema "Historiadores,

pp. 16-18; 11.522 (1969), pp. 14-20; "Comentários ao "Index Dioscoridis" de Amato Lusitano", O Médico, Nova série 50.905 (1969), pp.156-167.

87 Cf. José Lopes DiAs, "O clima de Lisboa, de Castelo Branco e da Guarda, segundo os comentários de Amato Lusitano", Estudos de Castelo Branco 25 (1968), pp. 138-156.

88 José Lopes DIAS, "Médicos portugueses da renascença vizinhos da Estremadura espanhola", O Médico, Nova série 66.1114 (1973), pp. 110-119; "Médicos portugueses da renascença vizinhos da estremadura espanhola", Notícias Médicas 2.97 (1973), p. 10; 15; 2.98 (1973), p. 10; 15.

89 Cf. José Lopes DiAs, "Iconographic memento on Amato Lusitanus (1511-1568)" in Centenário (IV) de João Rodrigues de Castelo Branco - Amato Lusitano, Castelo Branco, Estudos de Castelo Branco, 1968, pp. 69-86; "Iconographic memento on Amatus Lusitanus (1511-1568)", Estudos de Castelo Branco 28 (1968), pp. 117-130 com tradução portuguesa para "Memória iconográfica sobre Amato Lusitano", Estudos de Castelo Branco 28 (1968), pp. 131-134.

90 Cf, por exemplo, José Lopes DiAs, "Prefácio", in Centenário (IV) de João Rodrigues de Castelo Branco - Amato Lusitano. Castelo Branco, Estudos de Castelo Branco, 1968, pp. 7-12; José Lopes DiAs, "IV Centenário de João Rodrigues de Castelo Branco", O Médico, Nova série 50.916 (1969), pp. 1213-1214.

91 Cf., por exemplo, José Lopes DiAs; Firmino CRESPo (Introdução e notas), "Primeira Centúria de Curas Médicas de João Rodrigues de Castelo Branco (Amatus Lusitanus)", Arquivo de Patologia 16 (1944), pp. I-LIX. José Lopes DIAS; Firmino CRESPO, (Introdução e notas), "Segunda Centúria de Curas Médicas de João Rodrigues de Castelo Branco (Amatus Lusitanus)", Arquivo de Patologia 20 (1948). José Lopes DIAS; Firmino CRESPO, "Terceira Centúria de Amato Lusitano. Fragmentos da Introdução" Clínica Contemporânea 7.3 (1953), pp. 186-193. José Lopes DiAs; Firmino CRESPO (Introdução e notas), "Primeira Centúria de Curas Médicas de João Rodrigues de Castelo Branco (Amatus Lusitanus)", Arquivo de Patologia 16 (1944), pp. I-LIX. José Lopes DiAS; Firmino CRESPo (introdução e notas), "Segunda Centúria de Curas Médicas de João Rodrigues de Castelo Branco (Amatus Lusitanus)", Arquivo de Patologia 20 (1948).

92 Cf. José Lopes Dias, "Biografia de Amato Lusitano e outros ensaios amatianos", Estudos de Castelo Branco 37 (1971), pp. 3-234.

93 Cf. José Lopes DiAs, Amato Lusitano. Doutor João Rodrigues de Castelo Branco. Ensaio biobibliográfico. Lisboa, 1942. Este texto foi apresentado ao Congresso sobre a Actividade Científica Portuguesa (1940), constando no volume XIII do livro das comunicações. 
críticos, amigos e tradutores. Testamento profissional de Amato", um documento também importante na perspectiva da história da história.

\section{OUTROS ESTUDOS E OUTROS ESTUDIOSOS}

É longa a lista de autores e de estudiosos que publicaram em Portugal sobre Amato.

Independentemente da profundidade, rigor e extensão, alguns fizeram um retrato biográfico de Amato como é o caso de: Maximino Correia ${ }^{94}$, Diogo Barbosa Machado ${ }^{95}$, Rodrigues de Gusmão ${ }^{96}$, Sousa Viterbo ${ }^{97}$, Abílio Mendes $^{98}$, Barbosa Sueiro ${ }^{99}$, Ferreira de Mira ${ }^{100}$, Xavier Morato $^{101}$, A. Tavares de Sousa ${ }^{102}$, Eduardo Ricou ${ }^{103}$, José Manuel Pereira da Silva ${ }^{104}$, Garcia e

94 Cf. Maximino Correia, "[Amato Lusitano]". Revista Portuguesa de Medicina 5.6 (1956), pp. 181-184; Comemorações do IV Centenário da morte de Amato Lusitano. Estudos de Castelo Branco 27 (1968), pp. 5-21; "Alguns passos da vida de Amato Lusitano". Memórias da Academia das Ciências de Lisboa. Classe de Ciências 12 (1968), pp. 117-134; "Comemoração do IV Centenário da morte de Amato Lusitano na Academia das Ciências de Lisboa", in Centenário (IV) de João Rodrigues de Castelo Branco - Amato Lusitano. Castelo Branco, Estudos de Castelo Branco, 1968, pp. 13-28.

95 Cf. Diogo Barbosa MACHAdo, "Amato Lusitano" in Bibliotheca Lusitana, Tomo 1. Coimbra, Atlântida Editora, 1965, pp. 128-130 (Fac-simile da edição de Lisboa, Na Officina de Antonio Isidoro da Fonseca, 1741).

96 F. A. Rodrigues de Gusmão, "João Rodrigues de Castelo Branco", Coimbra Médica 5.10 (1885), pp. 170-171.

97 Cf. Sousa Viterbo, "Amato Lusitano", A Medicina Contemporânea 25.13 (1907), pp. 98-100; "Bibliografia. Amato Lusitano. A sua vida e a sua obra por Maximiano Lemos. 1 vol. de 212 pag. Porto 1907", A Medicina Contemporânea 25.11 (1907), pp. 82-84.

98 Cf. Abílio T. Mendes, "Doutor ]oão Rodrigues de Castelo Branco (Amato Lusitano) [artigo de polémica com José Lopes Dias]. Ao Dr. José Lopes Dias", O Médico. Nova série 36.723 (1965), pp. 100-101; "Doutor João Rodrigues de Castelo Branco (Amato Lusitano) - Nota biográfica", O Médico. Nova série 34.714 (1965), pp. 430-431.

99 Cf. Barbosa M. B. Sueıro, "A propósito de Amato Lusitano", Imprensa Médica 9.13-14 (1943), pp. $210 ; 221$.

100 Cf. Ferreira de MIRA, "Amato Lusitano", Médico Policlínico 3.44 (1980), pp. 41-44.

101 Cf. Xavier Morato, "[Amato Lusitano]", Revista Portuguesa de Medicina 5.6 (1956), pp. 1172-174.

102 Cf. A. Tavares de SousA, "[Amato Lusitano]", Revista Portuguesa de Medicina 5.6 (1956), pp. 174-178; "No quarto centenário da morte de Amato Lusitano" in Centenário (IV) de João Rodrigues de Castelo Branco - Amato Lusitano. Castelo Branco, Estudos de Castelo Branco, 1968, pp. 177-189; "No quarto centenário da morte de Amato Lusitano", Coimbra Médica 16.4, $3^{a}$ série (1969), pp. 303-314; "No quarto centenário da morte de Amato Lusitano", Estudos de Castelo Branco 29 (1969), pp. 8-20. Veja-se, também, "La valeur de l'oeuvre scientifique de Amatus Lusitanus, quatre siècles après sa mort", Clio Medica, Acta Academiae Internationalis Historiae Medicinae 7 (1972), pp. 69-72.

103 Cf. Eduardo Rıcou, "A longa jornada de Amato Lusitano", Jornal do Médico 125.2293 (1988), p. 732.

104 Cf. José Manuel Pereira da SILva, "Acerca de Amato Lusitano", Estudos de Castelo Branco 17 (1965), pp. 130-134; "Acerca de Amato Lusitano", Itinerário 1 (1965). 
Silva ${ }^{105}$, Pires de Lima ${ }^{106}$. Augusto d'Esaguy foca o Juramento de Amato Lusitano ${ }^{107}$. Alfredo Rasteiro, a propósito da medicina dos descobrimentos e da medicina judaica portuguesa aborda Amato Lusitano ${ }^{108}$, temática em que incide frequentemente noutras publicações.

Em obras gerais de autores portugueses sublinhem-se, por exemplo, Maximiano Lemos que, ao referir-se aos estudos da anatomia no Renascimento, sublinha que para esse período "ocorre logo o nome de um português, notável por muitos outros títulos, João Rodrigues de Castelo Branco, mais conhecido pelo nome de Amato Lusitano" ${ }^{109}$. J. A. Pires de Lima que refere que "a sua obra é notabilíssima e ocupa-se de vários ramos das ciências médicas" ${ }^{110}$, sublinhando que Amato se mostrou, também, como um "grande naturalista, nos seus comentários às obras de Dioscórides"111. M. Ferreira de Mira considerou que "os passos de Amato pelo mundo, e foram muitos, marcou-os ele próprio na sua obra científica: os Comentários aos dois primeiros livros de Dioscórides e as Centúrias de curas médicas" ${ }^{112}$. A. Tavares de Sousa que considera Amato como "o mais ilustre médico português do século Xvi" ${ }^{113}$.

Rocha Brito dedicou-se ao Juramento de Amato ${ }^{114}$, publicando e ocasionando reflexóes sobre a matéria ${ }^{115}$. Também teve semelhantes preocupaçôes Miller Guerra ${ }^{116}$.

105 Cf. L. Garcia e SILVA, "Amato Lusitano: um médico europeu no tempo dos descobrimentos", Acta Médica Portuguesa $2^{\text {a }}$ série 3:5 (1990), pp. 297-300.

106 Cf. F. C. Pires de LımA, "Amato Lusitano", in Verbo. Enciclopédia Luso-Brasileira de Cultura. Lisboa, Editorial Verbo, s.d., pp. 1621-1622.

107 Cf. Augusto d'Esaguy, Oração e Juramento Médico de Moisés Maimonide e Amato Lusitano. Lisboa, edição do autor, 1955.

108 Cf. Alfredo RASteiro, Medicina e descobrimentos. Coimbra, Livraria Almedina, 1992; Alfredo RASteIRo, Medicina judaica lusitana, século xvI. Coimbra, Quarteto, 2000, p. 71 e ss.

109 Cf. Maximiano Lemos, História da medicina em Portugal. Doutrinas e instituições. Lisboa, Publicações Dom Quixote/Ordem dos Médicos, 1991, p. 189.

110 Cf. J. A. Pires de LIMA, Epitome de história da medicina portuguesa. Porto, Portucalense Editora, SARL, 1943, p. 41.

111 Idem, Ibidem.

112 M. Ferreira de MIRA, História da medicina portuguesa. Lisboa, Edição da Empresa Nacional de Publicidade, 1948, p. 110.

113 Cf. A. Tavares de SousA, Curso de história da medicina. Das origens aos fins do século xvı. $2^{a}$ edição. Lisboa, FCG, 1996, p. 304. Na primeira edição da obra vide página 300.

114 Sobre o Juramento de Amato vejam-se, por exemplo, os artigos: "Juramento (0) de Amato Lusitano", Médico Hospitalar 12 (1998), pp. 31-32 e "Juramento de Amato Lusitano (um dos notáveis documentos médicos da renascença)", Clínica Contemporânea 3.28 (1949), pp. 1622-1623.

115 A. Rocha BRITO, "Poeira dos arquivos - juramento de Amato Lusitano", Coimbra Médica 4.1, 2a série, (1937), pp. 33-38.

116 Cf. Miller Guerra, "Amati Jusjurandum" in Centenário (IV) de João Rodrigues de Castelo Branco - Amato Lusitano. Castelo Branco, Estudos de Castelo Branco, 1968, pp. 173-175. "Amati Jusjurandum", Estudos de Castelo Branco 29 (1969), pp. 5-7. 
Silva Carvalho ocupou-se da relação de Amato com a urologia ${ }^{117}$. José Paiva Boléo preocupou-se com a invenção do obturador palatino ${ }^{118}$. Caria Mendes incidiu a sua atenção sobre Amato anatomista ${ }^{119}$, tal como Quintino Rogado. Por seu turno Luís de Pina tem, entre outros, um interessante estudo sobre as ideias de Amato em questôes psiquiátricas ${ }^{120}$ e de colaboração com Olívia Rúber de Meneses um estudo sobre as relaçóes da escola médica do Porto com os estudos biográficos de Amato ${ }^{121}$. Miller Guerra interessou-se pela obra científica de Amato Lusitano $^{122}$. Costa Sacadura estudou um caso clínico de Amato ${ }^{123}$.

Pelo seu valor historiográfico é de sublinhar com particular destaque a obra de A. J. Andrade Gouveia, Garcia d'Orta e Amato Lusitano na ciência do seu tempo, monografia com perto de 100 páginas e, do mesmo autor, Posiçóes de Garcia d'Orta e de Amato Lusitano na ciência do seu tempo ${ }^{124}$.

117 Cf. Augusto da Silva Carvalho, "João Rodrigues na história da urologia" in Homenagem ao Doutor João Rodrigues de Castelo Branco (Amato Lusitano). Castelo Branco, Câmara Municipal de Castelo Branco, 1955, pp. 137-141.

118 Cf. José de Paiva BolÉo, "Amatus Lusitanus, the inventor the palatine obturator", Estudos de Castelo Branco" 28 (1968), pp. 205-213; tradução em "Amatus Lusitanus inventor do obturador palatino", Estudos de Castelo Branco 28 (1968), p. 213. Veja-se também em "Amatus Lusitanus, the inventor the palatine obturator", in Centenário (IV) de João Rodrigues de Castelo Branco — Amato Lusitano. Castelo Branco, Estudos de Castelo Branco, 1968, pp. 159-172.

119 Cf. J. Caria Mendes, "Amatus Lusitanus anatomista", Estudos de Castelo Branco 28 (1968), pp. 179-204. "Amatus Lusitanus anatomista", in Centenário (IV) de João Rodrigues de Castelo Branco - Amato Lusitano. Castelo Branco, Estudos de Castelo Branco, 1968, pp. 133-158; "Amatus Lusitanus anatomista", Arquivo de Anatomia e Antropologia 35 (1971), pp. 269-291; "Amatus Lusitanus", Notícias Médicas 18:1812 (1989), pp. 11-12. Veja-se o trabalho de colaboração J. P. Miller GUERRA; J. Caria MENDES; L. Quintino RoGADo, "As válvulas das veias ázigos. As experiências de Amatus Lusitanus e a posição actual do problema", Jornal da Sociedade das Ciências Médicas de Lisboa 135:1 (1970), pp. 35-59. Ver também "As válvulas das veias ázigos. As experiências de Amatus Lusitanus e a posição actual do problema", Arquivo de Anatomia e Antropologia 35 (1971), pp. 147-167.

120 Cf. Luís de PINA, "Amato Lusitano na história da psiquiatria portuguesa", in Homenagem ao Doutor João Rodrigues de Castelo Branco (Amato Lusitano). Castelo Branco, Câmara Municipal de Castelo Branco, 1955, pp. 143-175. Veja-se também de Luís de Pina, "Amato Lusitano — lusitano e europeu", Imprensa Médica 20.6 (1956), pp. 342-350. Veja-se uma biografia muito sintética de "Amato em [Amato Lusitano]", Revista Portuguesa de Medicina 5.6 (1956), pp. 168-172.

121 Cf. Luís de Pina; Maria Olívia Rúber de Meneses, "A Escola Médica do Porto nos estudos biográficos e críticos de Amato Lusitano", Estudos de Castelo Branco 28 (1968), pp. 96-116. Veja-se também em: "A Escola Médica do Porto nos estudos biográficos e críticos de Amato Lusitano (no $4^{\circ}$ centenário da sua morte)" in Centenário (IV) de João Rodrigues de Castelo Branco - Amato Lusitano. Castelo Branco, Estudos de Castelo Branco, 1968, pp. 47-67.

122 Cf. Miller Guerra, "A obra científica de Amato Lusitano", Estudos de Castelo Branco 26 (1968), pp. 22-32; "A obra científica de Amato Lusitano", Memórias da Academia das Ciências de Lisboa. Classe de Ciências 12 (1968), pp. 135-146. Ver também "A obra científica de Amato Lusitano", in Centenário (IV) de João Rodrigues de Castelo Branco — Amato Lusitano. Castelo Branco, Estudos de Castelo Branco, 1968, pp. 29-39.

123 Cf. Costa SACADURA, "Certo caso, admirável mas verdadeiro, de uma mulher grávida, de que nos fala Amatus Lusitanus em 1564, repetido em nossos dias", A Medicina Contemporânea 73.7 (1955), pp. 347-350.

124 Cf. A. J. Andrade GouvelA, Garcia d'Orta e Amato Lusitano na ciência do seu tempo. Lisboa, Instituto de Cultura e Língua Portuguesa, 1985, 93 p.; do mesmo autor, "Posições de Garcia d'Orta e de Amato Lusitano na ciência do seu tempo" in História e Desenvolvimento da Ciência em Portugal, vol. 1. Lisboa, 
Mais recentemente assinalem-se também os estudos de Isilda Rodrigues sobre os problemas sexuais nas Centúrias de Amato Lusitano ${ }^{125}$.

\section{A TRADUÇÃO DAS CENTÚRIASE OUTROS ESTUDOS}

Firmino Crespo foi um tradutor das Centúrias de Amato. Legou-nos, também, alguns trabalhos de investigação sobre João Rodrigues ${ }^{126}$ e colaborou noutros trabalhos de co-autoria com José Lopes Dias ${ }^{127}$. Relativamente à tradução das Centúrias, assinale-se a edição, traduzida e prefaciada por Firmino Crespo, editada pela Faculdade de Ciências Médicas da Universidade Nova de Lisboa, obra em quatro volumes. No prefácio do primeiro volume, Firmino Crespo faz um breve historial das traduções para português das Centúrias de Amato, desde a proposta de José Lopes Dias, passando pela publicação das três primeiras centúrias, em 1946, 1949 e 1956, na revista do Instituto de Oncologia e no Arquivo de Patologia e, graças ao empenho de Francisco Gentil e de Mark Athias; passados mais de vinte anos, em 1979, Carlos dos Santos Reis intenta publicar as restantes Centúrias nos Anais do Instituto de Higiene e Medicina Tropical. Finalmente, a concretização, nos anos oitenta, em virtude do empenho de Luís Nuno Ferraz de Oliveira e da Faculdade de Ciências Médicas em patrocinar a edição completa das Centúrias ${ }^{128}$. Assinale-se, muito recentemente, a reedição das Centúrias traduzidas por Firmino Crespo numa edição da Ordem dos Médicos ${ }^{129}$. Trata-se de uma edição que retoma a versão de Firmino Crespo,

Publicações do II Centenário da Academia das Ciências de Lisboa, 1986, pp. 303-333. Veja-se "Severo de Melo, Garcia de Orta e Amato Lusitano na ciência do seu tempo", Vértice 46.470-472 (1986), p. 189.

125 Cf. Isilda Rodrigues, Amato Lusitano e as problemáticas sexuais - Algumas contribuições para uma nova perspetiva de análise das Centúrias de Curas Medicinais. Tese de Doutoramento - Universidade de Trás -os-Montes e Alto Douro. Vila Real, 2005. Veja-se, também, "Amato Lusitano e as questões sexuais - Algumas contribuições para uma nova perspectiva de análise das Centúrias de Curas Medicinais", Revista Portuguesa de Ciência das Religiões 11 (2007), pp. 317-333.

126 Cf. Firmino CRESPO, "Amato Lusitano revelado através da sua obra", in Centenário (IV) de João Rodrigues de Castelo Branco - Amato Lusitano. Castelo Branco, Estudos de Castelo Branco, 1968, pp. 193-204; "Amato Lusitano revelado através da sua obra", Estudos de Castelo Branco 29 (1969), pp. 23-24; "Bristol e Londres nas Centúrias de Amato Lusitano", Ocidente 76.369 (1969), pp. 4-5; "Amatus Lusitano, professor universitário de Ferrara", Ocidente. Revista Portuguesa de Cultura, Nova Série 80.393 (1971), pp. 36-38; "Alguns aspectos da vida e obra de Amato Lusitano", Medicina na Beira Interior. Da Pré-História ao Século xx - Cadernos de Cultura 8 (1994), pp. 3-4.

127 Cf. Firmino CRESPO; José Lopes DiAs (tradução), "Cura de Amato Lusitano de uma queda por coice de cavalo", Imprensa Médica 19.1 (1955), pp. 61-62; Firmino CRESPO; José Lopes DiAs, "Escorço biográfico [de Amato Lusitano]" in Homenagem ao Doutor João Rodrigues de Castelo Branco (Amato Lusitano). Castelo Branco, Câmara Municipal de Castelo Branco, 1955, pp. 215-250.

128 Cf. Amato Lusitano (João Rodrigues de Castelo Branco), Centúrias de curas medicinais. Lisboa, Universidade Nova de Lisboa - Faculdade de Ciências Médicas, s.d. [1980], 4 vols.

129 Cf. Amato Lusitano (João Rodrigues de Castelo Branco), Centúrias de curas medicinais. Lisboa, Centro Editor Livreiro da Ordem dos Médicos, 2010. 2 vols. Prefácio e tradução de Firmino Crespo com introdução de Pedro Nunes. 
com umas palavras de abertura de Pedro Nunes. Teria sido interessante que esta edição tivesse um estudo introdutório relevante, a propósito dos quinhentos anos do nascimento de Amato.

Muito úteis neste horizonte são, também, as publicaçôes de Américo da Costa Ramalho ${ }^{130}$. Assinalem-se e sublinhem-se, também, os estudos actuais de António Manuel Lopes Andrade sobre Amato Lusitano (vários aspectos biográficos) e ainda alguns estudos sobre algumas questôes contextuais e familiares de Amato. É o caso de Ciência, Negócio e Religião: Amato Lusitano em Antuérpia ${ }^{131}$; Os Senhores do Desterro de Portugal: Judeus portugueses em Veneza e Ferrara, em meados do século Xvi ${ }^{132}$; As tribulaçóes de Mestre João Rodrigues de Castelo Branco (Amato Lusitano) à chegada a Antuérpia, em 1534, em representação do mercador Henrique Pires, seu tio materno ${ }^{133}$; A mundividência de Diogo Pires à luz da colectânea poética dos Xenia ${ }^{134}$; A Senhora e os destinos da Nação Portuguesa: o caminho de Amato Lusitano e de Duarte Gomes ${ }^{135}$; Dioscórides renovado pela mão dos humanistas: os comentários de Amato Lusitano ${ }^{136}$.

Neste âmbito assinale-se ainda de António Andrade a entrada no Dizionario storico dell'Inquisizione sobre o tio de Amato, pai de Diogo Pires ${ }^{137}$. Sublinhe-se, também, a obra da responsabilidade de António Andrade, João Torrão, Jorge Costa; Júlio Costa (org.), Humanismo,

130 Cf. Américo da Costa Ramalho, "Prefácio" in Mário Santoro, Amato Lusitano ed Ancona. Coimbra, Centro de Estudos Clássicos e Humanísticos da Faculdade de Letras da Universidade de Coimbra / Instituto Nacional de Investigação Científica, 1991, 177 p. Vejam-se os artigos "A propósito do 'Amato Lusitano' de Ricardo Jorge", Revista Portuguesa de História 10 (1962), pp. 501-508. Veja-se também "A propósito do "Amato Lusitano" de Ricardo Jorge", in Estudos sobre a época do Renascimento, Coimbra, 1969, pp. 187-195.

131 António Manuel Lopes AndRADE, "Ciência, Negócio e Religião: Amato Lusitano em Antuérpia", in Inês de Ornellas e CASTRO; Vanda ANASTÁCIO (coord.). Revisitar os Saberes - Referências Clássicas na Cultura Portuguesa do Renascimento à Época Moderna. Lisboa, Centro de Estudos Clássicos - Faculdade de Letras da Universidade de Lisboa, 2010, pp. 9-49.

132 António Manuel Lopes ANDRADE, "Os Senhores do Desterro de Portugal: Judeus portugueses em Veneza e Ferrara, em meados do século xvI", Veredas - Revista da Associação Internacional de Lusitanistas 6 (2006), pp. 65-108.

133 António Manuel Lopes ANDRADE, "As tribulações de Mestre João Rodrigues de Castelo Branco (Amato Lusitano) à chegada a Antuérpia, em 1534, em representação do mercador Henrique Pires, seu tio materno", Medicina na Beira Interior. Da Pré-História ao séc. XxI - Cadernos de Cultura 23 (2009), pp. 7-14

134 António Manuel Lopes ANDRADE, "A mundividência de Diogo Pires à luz da colectânea poética dos Kenia", in Francisco de Oliveıra; Cláudia TeıxeIra; Paula Barata Dias (Coords.), Espaços e Paisagens: Antiguidade Clássica e Heranças Contemporâneas. Vol. 2. Línguas e Literaturas. Idade Média. Renascimento. Recepção. Coimbra, Associação Portuguesa de Estudos Clássicos - Centro de Estudos Clássicos e Humanísticos da Universidade de Coimbra, 2009, p. 345-351. Trata-se de uma colectânea poética que resultou da parceria entre Diogo Pires e Amato, amigos e primos direitos, inspirada em parte nos comentários a Dioscórides.

135 António Manuel Lopes ANDRADE, "A Senhora e os destinos da Nação Portuguesa: o caminho de Amato Lusitano e de Duarte Gomes", Cadernos de Estudos Sefarditas 10.11 (2011), pp. 87-130.

136 António Manuel Lopes ANDRADE, "Dioscórides renovado pela mão dos humanistas: os comentários de Amato Lusitano", in Carmen SoARes (Coord.), Espaços do Pensamento Científico da Antiguidade. Volume I. Coimbra, Imprensa da Universidade de Coimbra, 2013, pp. 71-90.

137 António Manuel Lopes ANDRADE, s. v. PIRES, Henrique: Dizionario storico dell'Inquisizione, diretto da Adriano Prosperi con la collaborazione di Vincenzo Lavenia e John Tedeschi. Pisa, Edizioni della Normale, 2010. 
Diáspora e Ciência (séculos XVI e XVII): estudos, catálogo, exposiçāô ${ }^{138}$. Trata-se de um volume que provém do Colóquio Internacional «Humanismo, Diáspora e Ciência» e da Exposição Bibliográfica, realizados na Biblioteca Pública Municipal do Porto, entre 7 e 8 de Março de 2013. Neste volume assinalem-se os estudos António Manuel Lopes Andrade, Amato Lusitano, Diogo Pires e Pedro Santerna: os caminhos entrecruzados de um médico, de um poeta e de um jurisconsulto portugueses ${ }^{139}$; Virgínia Soares Pereira, Plantas de uso terapêutico e alimentar em Amato Lusitano e Diogo Pires ${ }^{140 "}$. Nesta linha de estudos salientem-se ainda os trabalhos seguintes: António Manuel Lopes Andrade; Hugo Miguel Crespo, Os inventários dos bens de Amato Lusitano, Francisco Barbosa e Joseph Molcho, em Ancona, na fuga à Inquisição (1555) ${ }^{141}$; João Manuel Nunes Torrão, Marcelo Virgílio e Amato Lusitano: a utilização do saber alheio para a lenta construção de um saber próprio (breves indicaçôes) ${ }^{142}$; António Guimarães Pinto, Ciência e Preconceito: $O$ ataque de Pietro Andrea Mattioli a Amato Lusitano ${ }^{143}$; Ana Alexandra Macedo Lima, La melancolía en las Primeira y Segunda Centúrias de Curas Medicinais de Amato Lusita$n o^{144}$. Na obra-catálogo, Arte Médica e Imagem do Corpo. De Hipócrates ao final do século XviII são várias as referências aos trabalhos de Amato Lusitano ${ }^{145}$.

138 António ANDRADE; João ToRRÃo; Jorge Costa; Júlio Costa (org.), Humanismo, Diáspora e Ciência (séculos xVI exVII): estudos, catálogo, exposição. Porto, Câmara Municipal do Porto, Biblioteca Pública Municipal; Universidade de Aveiro, Centro de Línguas e Culturas, 2013.

139 António Manuel Lopes AndRAde, "Amato Lusitano, Diogo Pires e Pedro Santerna: os caminhos entrecruzados de um médico, de um poeta e de um jurisconsulto portugueses", in António ANDRADE; João TORRÃo; Jorge COSTA; Júlio Costa (org.), Humanismo, Diáspora e Ciência (séculos XVI e XVII): estudos, catálogo, exposição. Porto, Câmara Municipal do Porto, Biblioteca Pública Municipal; Universidade de Aveiro, Centro de Línguas e Culturas, 2013, pp. 117-138.

140 Virgínia Soares Pereira, "Plantas de uso terapêutico e alimentar em Amato Lusitano e Diogo Pires", in António ANDRADE; João ToRRÃo; Jorge CostA; Júlio Costa (org.). Humanismo, Diáspora e Ciência (séculos XVI exVII): estudos, catálogo, exposição. Porto, Câmara Municipal do Porto, Biblioteca Pública Municipal; Universidade de Aveiro, Centro de Línguas e Culturas, 2013, pp. 313-326.

141 António Manuel Lopes ANDRADE; Hugo Miguel CRESPo, "Os inventários dos bens de Amato Lusitano, Francisco Barbosa e Joseph Molcho, em Ancona, na fuga à Inquisição (1555)", Ágora. Estudos Clássicos em Debate 14.1 (2012), pp. 45-90.

142 João Manuel Nunes TorRÃo, "Marcelo Virgílio e Amato Lusitano: a utilização do saber alheio para a lenta construção de um saber próprio (breves indicações)", in Maria Cristina PIMENTEL; Paulo Farmhouse AlBerto (eds.), Vir bonus peritissimus aeque. Estudos de homenagem a Arnaldo do Espírito Santo. Lisboa, Centro de Estudos Clássicos, 2013, pp. 601-610.

143 António Guimarães PInTo, "Ciência e Preconceito: O ataque de Pietro Andrea Mattioli a Amato Lusitano", Humanitas 65 (2013), pp. 157-182.

144 Ana Alexandra Macedo LiMA, "La melancolía en las Primeira y Segunda Centúrias de Curas Medicinais de Amato Lusitano", in Manuel Lázaro Pulido, José Luis Fuertes Herreros, Ángel Poncela González (coord..), La filosofía de las pasiones y la Escuela de Salamanca: Edad Media y Moderna, 2013, pp. 87-97. Da mesma autora também "La melancolía en la Primeira y Segunda Centúrias de Curas Medicinais de Amato Lusitano", Cauriensia: revista anual de Ciencias Eclesiásticas 7 (2012), pp. 89-99.

145 Cf. Adelino Cardoso, António Braz de Oliveira; Manuel Silvério Maroues (coord.), Arte Médica e Imagem do Corpo. De Hipócrates ao final do século XVIII. Lisboa, Biblioteca Nacional de Portugal, 2010. 


\section{OUTROS TEXTOS}

Diversos artigos de reduzidas dimensóes ou de tipo nota abordam a figura de Amato. Compilámos textos desta natureza em publicaçôes como O Bacilo $(1963)^{146}$ e a Revista da Associação Portuguesa de Clinicas Privadas de Hemodiálise (1994) ${ }^{147}$. Manuel Freitas e Costa na obra Personalidades e grandes vultos da medicina portuguesa através dos séculos tem uma entrada com Amato Lusitano $^{148}$. Manuel Machado Macedo na obra panorâmica sobre a medicina em Portugal no século xx intitulada História da Medicina Portuguesa no século xx refere Amato o que acentua a sua condição de vulto incontornável da medicina do nosso país ${ }^{149}$. Assinale-se, também, uma publicação de natureza educativa da autoria de Maria Adelaide Neto Salvado e Maria de Lurdes Pires Cardoso intitulada $O$ horto de Amato Lusitano. Uma ponte para cultura, educação e cidadania ${ }^{150}$.

\section{VOLUMES MONOGRÁFICOS E PUBLICAÇÕES PERIÓDICAS}

Um volume intitulado Homenagem ao Doutor João Rodrigues de Castelo Branco (Amato Lusitano), editado em Castelo Branco em 1955 e prefaciado por José Lopes Dias constitui também um valioso estudo colectivo sobre Amato. Nas 250 páginas da obra encontramos trabalhos de vários autores, alguns já referidos, sendo outros estrangeiros. É igualmente de registar o grosso volume de cerca de 200 páginas, comemorativo do IV Centenário de Joáo Rodrigues de Castelo Branco — Amato Lusitano, prefaciado por José Lopes Dias e editado em $1968^{151}$.

A revista Estudos de Castelo Branco cuja publicação se iniciou em 1961 constitui um espólio de enorme valor para o estudo da vida e obra de Amato Lusitano, dada a qualidade dos artigos que encerra sobre o médico albicastrense, muitos dos quais já referidos.

Incontornável é a publicação Medicina na Beira Interior. Da Pré-História ao Século XxI - Cadernos de Cultura ${ }^{152}$ pois apresenta para o estudo da vida e obra de Amato Lusitano, contributos

146 Cf. "João Rodrigues Castelo Branco — Amato Lusitano (1511-1568)", O Bacilo. za série 2 (1963), pp. 3; 15-16.

147 Cf. "História (Da)... João Rodrigues de Castelo Branco", Revista da Associação Portuguesa de Clínicas Privadas de Hemodiálise 1 (1994), p. 21.

148 Manuel Freitas e Costa na obra Personalidades e grandes vultos da medicina portuguesa através dos séculos. Lisboa, Lidel, 2010, pp. 143-144.

149 Cf. Manuel Machado MACEDo, História da Medicina Portuguesa no século xx. Lisboa, CTTCorreios, 1999, p. 17.

150 Cf. Maria Adelaide Neto SAlvado; Maria de Lurdes Pires CARdoso, O horto de Amato Lusitano. Uma ponte para cultura, educação e cidadania. Castelo Branco, 2004.

151 Cf. Centenário (IV) de João Rodrigues de Castelo Branco - Amato Lusitano (Prefácio de José Lopes Dias). Castelo Branco, Estudos de Castelo Branco, 1968, 204 p.

152 Além da consulta obrigatória da revista veja-se, também, Maria Adelaide Neto SALVADo; António Lourenço Maroues (orgs.), Amato Lusitano nos Cadernos de Cultura "Medicina na Beira Interior - Da Pré-História ao Século xxı, Castelo Branco, Semedo Sociedade Tipográfica, Lda, 2004. 
muito diversificados de vários autores como António Andrade (já referido) e em colaboração com José Sílvio Moreira Fernandes ${ }^{153}$, Romero Bandeira ${ }^{154}$, Maria de Lourdes Barata ${ }^{155}$, Firmino Crespo ${ }^{156}$, Fanny Xavier da Cunha ${ }^{157}$, A. M. Lopes Dias ${ }^{158}$, António Lourenço Marques ${ }^{159}$,

153 Cf. José Sílvio Moreira Fernandes; António Manuel Lopes ANDRADE, "A pedra bezoar e o unicórnio nos comentários de Amato Lusitano a Dioscórides: propriedades, valor, tradição e tradução", Medicina na Beira Interior. Da Pré-História ao Século xxI — Cadernos de Cultura 24 (2010), pp. 35-40.

154 Cf. Romero BANDEIRA, "Amato, médico sem fronteiras", Medicina na Beira Interior. Da Pré-História ao Século Xx - Cadernos de Cultura 10 (1996), pp. 45-46. Romero BANDEIRA; José Viana PINHEIRo; Mário LOPES, "Evolução e conceitos revendo o Juramento de Amato. O segredo na iatroética", Medicina na Beira Interior. Da Pré-História ao Século xx — Cadernos de Cultura 6 (1993), pp. 22-23.

155 Maria de Lurdes Gouveia da Costa Barata, "Um poder do fogo - de Amato Lusitano aos poetas", Medicina na Beira Interior. Da Pré-História ao Século xxI - Cadernos de Cultura 14 (2000), pp. 58-63.

156 Cf. Firmino CRESPo, "Alguns aspectos da vida e obra de Amato Lusitano", Medicina na Beira Interior. Da Pré-História ao Século xx - Cadernos de Cultura 8 (1994), pp. 3-4.

157 Cf. Fanny Andrée Font Xavier da CUNHA, "A arte de curar em Amato Lusitano (1511-1568) e o quotidiano terapêutico português no século XVIII. Panaceias nossas de cada dia, "ontem e hoje" ". Medicina na Beira Interior. Da Pré-História ao Século xx — Cadernos de Cultura 9 (1995), pp. 11-19; "A alimentação na obra de Amato Lusitano (1511-1568)", Medicina na Beira Interior. Da Pré-História ao Séculoxx - Cadernos de Cultura 11 (1997), pp. 9-14; "A água, medicina universal, e Amato Lusitano (1511-1568)", Medicina na Beira Interior. Da Pré-História ao Século xx — Cadernos de Cultura 13 (1999), pp. 10-16; "O "fogo" na obra de Amato Lusitano", Medicina na Beira Interior. Da Pré-História ao Século xxI - Cadernos de Cultura 14 (2000) pp. 30-33; "A cultura clássica nas obras de dois grandes autores-médicos naturais da Beira Interior: Amato Lusitano e Ribeiro Sanches", Medicina na Beira Interior. Da Pré-História ao SéculoxxI —Cadernos de Cultura 15 (2001), pp. 30-37; "Amato Lusitano (1511-1568) e o homem esse desconhecido", Medicina na Beira Interior. Da Pré-História ao Século xxI - Cadernos de Cultura 20 (2006), pp. 42-45; "As terapêuticas preferenciais de Amato Lusitano (1511-1568) e seu ressurgimento", Medicina na Beira Interior. Da Pré-História ao Século xxI - Cadernos de Cultura 21 (2007), pp. 32-35; "A cirurgia na obra de Amato Lusitano", Medicina na Beira Interior. Da Pré-História ao Século xxI — Cadernos de Cultura 23 (2009), pp. 20-22.

158 Cf. A. M. Lopes DiAs, "Algumas plantas aromáticas usadas por Amato Lusitano", Medicina na Beira Interior. Da Pré-História ao Século xx - Cadernos de Cultura 5 (1992), pp. 16-18; "Plantas usadas por Amato Lusitano. Sua localização em solos aráveis do Distrito de Castelo Branco, algumas em perigo de extinção", Medicina na Beira Interior. Da Pré-História ao Século xx — Cadernos de Cultura 6 (1993), pp. 24-28; "Estudo da Primeira Centúria de Amato Lusitano - 0 uso das plantas, imagens de aromáticas da região da Serra da Estrela e abordagem da sua composição florística", Medicina na Beira Interior. Da Pré-História ao Século xx - Cadernos de Cultura 8 (1994), pp. 11-16; "Notícias das plantas medicinais e aromáticas da $2^{\text {a }}$ Centúria de Amato Lusitano. Achegas para o estudo da ecologia de vegetação da Beira Interior", Medicina na Beira Interior. Da Pré-História ao Séculoxx - Cadernos de Cultura 9 (1995), pp. 25-30; "A influência mediterrânica na vida científica do século xvı. A botânica da bacia mediterrânica em Amato Lusitano", Medicina na Beira Interior. Da Pré-História ao Século xx — Cadernos de Cultura. 11 (1997), pp. 32-36

159 Cf. António Lourenço MARQues, "Para a história da morte do século xVI. A certificação da morte em Amato Lusitano e as novas artes de morrer em Frei Heitor Pinto" Medicina na Beira Interior. Da Pré-História ao Séculoxx - Cadernos de Cultura 2 (1990), pp. 26-30; "A medicina e o médico perante o doente incurável e moribundo no século xVI — testemunhos de Amato Lusitano", Medicina na Beira Interior. Da Pré-História ao Século xx - Cadernos de Cultura 4 (1991), pp. 13-15; "A realidade da dor nas curas de Amato Lusitano", Medicina na Beira Interior. Da Pré-História ao Século xx - Cadernos de Cultura 5 (1992), pp. 19-22; "A velhice no tempo de Amato Lusitano", Medicina na Beira Interior. Da Pré-História ao Século xx — Cadernos de Cultura,"À procura da idade do cancro nas Centúrias de Amato Lusitano", Medicina na Beira Interior. Da Pré-História ao Século xx - Cadernos de Cultura 9 (1995), pp. 21-24; "Amarguras do nascimento e o génio de Amato Lusitano", Medicina na Beira Interior. Da Pré-História ao Século xx - Cadernos de Cultura 10 (1996), pp. 21-24; "O vinho na época de Amato lusitano: consolo, sustento e alívio", Medicina na 
Albano Mendes de Matos ${ }^{160}$, Manuel Lourenço Nunes ${ }^{161}$, José Morgado Pereira ${ }^{162}$, Alfredo Rasteiro ${ }^{163}$,

Beira Interior. Da Pré-História ao Século xx - Cadernos de Cultura 11 (1997), pp. 23-26; "A água e a vida quotidiana à luz das IV e V centúrias de curas medicinais de Amato Lusitano", Medicina na Beira Interior. Da Pré-História ao Século xx — Cadernos de Cultura 13 (1999), pp. 19-21; "Os quatro elementos e a vida quotidiana dos doentes na obra de Amato Lusitano", Medicina na Beira Interior. Da Pré-História ao Século XXI - Cadernos de Cultura 14 (2000), pp. 34-37; "Amato Lusitano e o uso da palavra médica na tradição hipocrática", Medicina na Beira Interior. Da Pré-História ao Século xxI — Cadernos de Cultura 15 (2001), pp. 25-29; "Os temas Universais em Amato Lusitano", Medicina na Beira Interior. Da Pré-História ao Século XXI - Cadernos de Cultura 16 (2002), pp. 25-28; "Saberes efémeros duradouros — o caso da sangria com passagem por Amato Lusitano", Medicina na Beira Interior. Da Pré-História ao SéculoxxI —Cadernos de Cultura 18 (2004), pp. 38-43; "Sentir dor no tempo de Amato Lusitano", Medicina na Beira Interior. Da Pré-História ao Século xx। - Cadernos de Cultura 20 (2006), pp. 37-41.

160 Cf. Albano Mendes de Matos, "A mulher e as suas doenças em Amato Lusitano", Medicina na Beira Interior. Da Pré-História ao Século xx - Cadernos de Cultura 10 (1996), 9-11; "Os produtos de origem animal na terapêutica de Amato Lusitano", Medicina na Beira Interior. Da Pré-História ao Século xx — Cadernos de Cultura 12 (1998), pp. 13-19.

161 Cf. Manuel Lourenço Nunes, "A saúde oral em Amato Lusitano", Medicina na Beira Interior. Da Pré-História ao Século xx - Cadernos de Cultura 12 (1998), pp. 25-26.

162 Cf. José Morgado Pereira, "A melancolia nas centúrias de Amato Lusitano", Medicina na Beira Interior. Da Pré-História ao Século xx - Cadernos de Cultura 7 (1993), pp. 3-5; "A doença e a condição feminina em Amato", Medicina na Beira Interior. Da Pré-História ao Século xx - Cadernos de Cultura 12 (1998), pp. 21-23; "Os comportamentos alimentares nas centúrias de curas medicinais", Medicina na Beira Interior. Da Pré-História ao Século xx - Cadernos de Cultura 12 (1998), pp. 4-7; "A ironia em Amato Lusitano", Medicina na Beira Interior. Da Pré-História ao Século xx — Cadernos de Cultura 13 (1999), pp. 30-33; "A epilepsia nas Centúrias de Curas Medicinais", Medicina na Beira Interior. Da Pré-História ao Século xx। - Cadernos de Cultura 15 (2001), pp. 22-24; "Amato Lusitano e as fronteiras da prática médica", Medicina na Beira Interior. Da Pré-História ao Século xxI - Cadernos de Cultura 16 (2002), pp. 29-32; "Considerações sobre o Morbo Gallico nas Centúrias de Amato Lusitano". Medicina na Beira Interior. Da Pré-História ao Século xxI — Cadernos de Cultura 17 (2003), pp. 31-35.

163 Cf. Alfredo RASTEIRO, "João Rodrigues de Castelo Branco e a solidariedade médica na luta contra a doença e a morte", Medicina na Beira Interior. Da Pré-História ao Séculoxx — Cadernos de Cultura 1 (1989), pp. 16-18; "Memória de Amato", Medicina na Beira Interior. Da Pré-História ao Séculoxx — Cadernos de Cultura. 5 (1992), pp. 3-7; "Amato, Vesálio, Paré e os traumatismos da cabeça em 1559", Medicina na Beira Interior. Da Pré-História ao Séculoxx —Cadernos de Cultura 6 (1993), pp. 20-21; "Amato, Montalto e a arte dos olhos nos séculos XVI e XVII", Medicina na Beira Interior. Da Pré-História ao Século xx — Cadernos de Cultura 8 (1994), pp. 5-9; "Amato e os nasci", Medicina na Beira Interior. Da Pré-História ao Século xx - Cadernos de Cultura 9 (1995), pp. 3-10; "A mulher, o sofrimento e a compaixão na obra de Amato Lusitano", Medicina na Beira Interior. Da Pré-História ao Século xx — Cadernos de Cultura 10 (1996), pp. 13-20; "A receita do "manjar de fígados" do Doutor Amato Lusitano (1511-1658)", Medicina na Beira Interior. Da Pré-História ao Séculoxx — Cadernos de Cultura 11 (1997), pp. 3-7; "Salamanca e os Lusitanos", Medicina na Beira Interior. Da Pré-História ao Séculoxx — Cadernos de Cultura 11 (1997) pp. 66-69; "Índias de Castela e Índias de Portugal na obra de Amato Lusitano", Medicina na Beira Interior. Da Pré-História ao Século xx - Cadernos de Cultura 12 (1998), pp. 8-11; "A água em "De Medica Materia", Dioscórides, segundo Amato Lusitano e Andres Laguna", Medicina na Beira Interior. Da Pré-História ao Século xx — Cadernos de Cultura 13 (1999), pp. 5-9; "Quatro elementos, reacção Hipocrática, Amato Lusitano e "O Múmia", Medicina na Beira Interior. Da Pré-História ao Século xx। — Cadernos de Cultura 14 (2000), pp. 13-18; "Cultura clássica, barbarismos e arcaísmos em Amato Lusitano (1511-1568)", Medicina na Beira Interior. Da Pré-História ao Século xxI —Cadernos de Cultura 15 (2001), pp. 10-14; "Amato Lusitano — Fronteiras políticas, religiosas e linguísticas", Medicina na Beira Interior. Da Pré-História ao Século xx। —Cadernos de Cultura 16 (2002), pp. 11-18; "Religião, medicação e informação / desinformação na época de Amato Lusitano", Medicina na Beira Interior. Da Pré-História ao Século xx। — Cadernos de Cultura 17 (2003), pp. 18-22; "Amato Lusitano e a medicina das navegações no século xvı", Medicina na Beira Interior. Da Pré-História ao Século xxı - Cadernos de Cultura. 18 (2004), pp. 24-28; "Amato Lusitano (1511-1568). Tensões e diferenças na Europa do século xvı", Medicina na Beira Interior. Da Pré-História ao Século xxı - Cadernos de Cultura 19 (2005), pp. 6-16; "Escorbuto, pepinos, inquisição e opúncias na época de Amato Lusitano (1511-1568)", Medicina na Beira Interior. Da Pré-História ao Século xxI Cadernos de Cultura 20 (2006), pp. 23-36; "Amato Lusitano (1511-1568). Religião e imagem", Medicina na Beira In- 
Maria Adelaide Neto Salvado ${ }^{164}$, Daniel Cartucho, Gabriela Valadas ${ }^{165}$, João Maria Nabais ${ }^{166}$,
Maria de Lurdes Cardoso $^{167}$, Maria de Fátima Paixão, Fátima Regina Jorge, Ana Isabel Flórido ${ }^{168}$,

terior. Da Pré-História ao Século xx। - Cadernos de Cultura 21 (2007), pp. 28-31; "Calcanhar de Amato", Medicina na Beira Interior. Da Pré-História ao Século xx। — Cadernos de Cultura 22 (2008), pp. 17-25; "Amigos de Amato, cidadãos do mundo", Medicina na Beira Interior. Da Pré-História ao Século xx। - Cadernos de Cultura 23 (2009), pp. 15-19; "O Juramento do Doutor Amato e o compromisso dos essénios", Medicina na Beira Interior. Da Pré-História ao Século XXI - Cadernos de Cultura 24 (2010); "Doutor Amado (1511-1568), sete apontamentos", Medicina na Beira Interior. Da Pré-História ao Século xxI - Cadernos de Cultura 27 (2013), pp. 13-22.

164 Cf. Maria Adelaide Neto SAlvado, "O espaço geográfico nas centúrias de Amato", Medicina na Beira Interior. Da Pré-História ao Séculoxx — Cadernos de Cultura 5 (1992), pp. 9-15; "Catástrofes naturais na visão de Amato Lusitano", Medicina na Beira Interior. Da Pré-História ao Séculoxx - Cadernos de Cultura 6 (1993), pp. 15-19; "A mulher do século xVI no olhar de Amato Lusitano", Medicina na Beira Interior. Da Pré-História ao Século xx - Cadernos de Cultura 10 (1996), pp. 3-8; "Os frutos e as leguminosas nas Centúrias de Curas Medicinais de Amato Lusitano", Medicina na Beira Interior. Da Pré-História ao Séculoxx - Cadernos de Cultura 11 (1997), pp. 15-21; "As águas santas — das velhas crenças à voz de Amato Lusitano", Medicina na Beira Interior. Da Pré-História ao Século xx — Cadernos de Cultura 13 (1999) pp. 23-29; "Os quatro elementos, os astros, as doenças e o homem - a visão de Amato Lusitano", Medicina na Beira Interior. Da Pré-História ao Século xx। - Cadernos de Cultura 14 (2000), pp. 21-28; "A História Natural de Plínio, o Velho, no olhar de Amato Lusitano", Medicina na Beira Interior. Da Pré-História ao Século xx — Cadernos de Cultura 15 (2001), pp. 15-21; "Amato Lusitano - Médico sem Fronteiras em Ragusa do Séc. Xvı", Medicina na Beira Interior. Da Pré-História ao Século xxı — Cadernos de Cultura 16 (2002), pp. 19-24; "De Amato Lusitano a Mircea eliade - os elos de religação", Medicina na Beira Interior. Da Pré-História ao Século xxı — Cadernos de Cultura 17 (2003), pp. 23-30; "O "mau olhado" em dois tratados de medicos portugueses contemporaneous de Amato Lusitano", Medicina na Beira Interior. Da Pré-História ao Século xx। - Cadernos de Cultura 19 (2005), pp. 25-35; "De um caso de raiva contado por Amato Lusitano, em Salónica do século XVI, aos casos de raiva na região de Castelo Branco em finais do século XIX", Medicina na Beira Interior. Da Pré-História ao Século XXI — Cadernos de Cultura 20 (2006), pp. 47-54; "Dos casos de varíola tratados por Amato Lusitano na 3 a centúria às epidemias de varíola na Beira Interior em finais do século XIX", Medicina na Beira Interior. Da Pré-História ao Século xXI — Cadernos de Cultura 22 (2008), pp. 49-55; "Amato - 'amável de nome e de facto' ". Medicina na Beira Interior. Da Pré-História ao Século xx। Cadernos de Cultura 23 (2009), pp. 36-38.

165 Cf. Daniel CARTUCHO; Gabriela VALADAS, "Abcessos de drenagem pura e branca - a propósito de uma cura em Amato Lusitano", Medicina na Beira Interior. Da Pré-História ao Século xxI - Cadernos de Cultura 16 (2002), pp. 33-36.

166 Cf. João Maria NABAIS, "A importância de Amato Lusitano na medicina do século xvı", Medicina na Beira Interior. Da Pré-História ao Século xxI — Cadernos de Cultura 16 (2002), pp. 37-40; "Garcia de Orta, um contemporâneo de Amato (médico naturalista do século xvı: cerca 1500-1568)", Medicina na Beira Interior. Da Pré-História ao Século xxI - Cadernos de Cultura 18 (2004), pp. 44-48; "Contributos de Amato Lusitano para a história das religiões e da ciência", Medicina na Beira Interior. Da Pré-História ao Século xxı - Cadernos de Cultura 21 (2007), pp. 48-54; "A criança no tempo de Amato Lusitano, uma análise historiográfica das centúrias de curas medicinais", Medicina na Beira Interior. Da Pré-História ao Século xxI - Cadernos de Cultura 23 (2009), pp. 53-62; "O humanismo na medicina: a importância de Amato Lusitano na visão ecumenical de Ricardo Jorge", Medicina na Beira Interior. Da Pré-História ao Século xxI - Cadernos de Cultura 24 (2010), pp. 21-27.

167 Cf. Maria de Lurdes CARDoso, "História da ciência e ensino das ciências - a história da ciência a partir da vida e obra de Amato Lusitano", Medicina na Beira Interior. Da Pré-História ao Século xxI Cadernos de Cultura 16 (2002), pp. 79-80; "O cruzamento de olhares: humanismo em Amato Lusitano e Luís Vives", Medicina na Beira Interior. Da Pré-História ao Século xx। — Cadernos de Cultura 23 (2009), pp. 39-43; "Saúde e ambiente - perspectives amatianas e darwinianas", Medicina na Beira Interior. Da Pré-História ao Século xxı — Cadernos de Cultura 24 (2010), pp. 28-35.

168 Maria de Fátima PaIXÃo; Fátima Regina JoRGE; Ana Isabel FlóRIDo, "Pesos e medidas na obra de Amato Lusitano: dos saberes e das certezas da época", Medicina na Beira Interior. Da Pré-História ao Século xxI - Cadernos de Cultura 19 (2005), pp. 17-24. 
Manuel Costa Alves ${ }^{169}$, Maria José Leal ${ }^{170}$, Aires Gameiro ${ }^{171}$, Armando Moreno ${ }^{172}$, J. A. David de Morais ${ }^{173}$; Isilda Teixeira Rodrigues ${ }^{174}$, Pedro Salvado ${ }^{175}$, António Romeiro Carvalho $^{176}$, António Maria Martins Melo ${ }^{177}$, Maria do Sameiro Barroso ${ }^{178}$, Ana Margarida Borges $^{179}$, Emília Oliveira ${ }^{180}$. De todos estes sublinhamos os nomes de Alfredo Rasteiro e António Lourenço Marques, mas também de José Morgado Pereira, Maria Adelaide Neto Salvado e Fanny Xavier da Cunha ${ }^{181}$ pelos estudos que realizaram e continuam a realizar sobre

169 Manuel Costa Alves, "Amato Lusitano e a doença de D. Sebastião", Medicina na Beira Interior. Da Pré-História ao Século xxI - Cadernos de Cultura 19 (2005), pp. 36-39.

170 Maria José LeAL, "As incursões de Amatus Lusitanus pela cirurgia pediátrica", Medicina na Beira Interior. Da Pré-História ao Século xxI — Cadernos de Cultura 22 (2008), pp. 29-34; "Nempe color — o preceito galenico nas centúrias de Amato Lusitano", Medicina na Beira Interior. Da Pré-História ao Século xx। Cadernos de Cultura 24 (2010), pp. 16-20; "O caminho de Hades - o verbo, a palavra, a voz de Amato", Medicina na Beira Interior. Da Pré-História ao Século xxI — Cadernos de Cultura 27 (2013), pp. 23-26.

171 Aires GameIro, "Amato Lusitano (1511-1568) e S. João de Deus (1495-1550): contemporâneos, aventureiros e cuidadores de doentes com princípios éticos", Medicina na Beira Interior. Da Pré-História ao Século xxI - Cadernos de Cultura 22 (2008), pp. 35-43.

172 Armando Moreno, "Ética em Amato Lusitano", Medicina na Beira Interior. Da Pré-História ao Século xxı - Cadernos de Cultura 23 (2009), pp. 55-86; "Os mitos em Amato Lusitano", Medicina na Beira Interior. Da Pré-História ao Século xxI - Cadernos de Cultura 23 (2009) pp. 23-29.

173 J. A. David de Morals, "O tratamento vernáculo do cobro (herpes zoster) nas Centúrias de Amato Lusitano e no Sul de Portugal: abordagem médico-antropológica", Medicina na Beira Interior. Da Pré-História ao Século xxI - Cadernos de Cultura 21 (2007), pp. 43-47; "Ainda a questão do desaparecimento do túmulo de Amato Lusitano", Medicina na Beira Interior. Da Pré-História ao Século xxı - Cadernos de Cultura 27 (2013), pp. 7-12; "O mercador de Salónica, o seu gato e os seus criados: contribuição para o estudo das zoonoses nas "Centurias" de Amato Lusitano", Medicina na Beira Interior. Da Pré-História ao Século xxI - Cadernos de Cultura 24 (2010), pp. 31-34.

174 Isilda Teixeira Rodrigues, "Paralelismos e divergencias entre as Centúrias e o traité des Monstres et des Prodiges", Medicina na Beira Interior. Da Pré-História ao Século xx। — Cadernos de Cultura 23 (2009) pp. 30-35; "O contributo de Amato Lusitano para a história da sexologia", Medicina na Beira Interior. Da Pré-História ao Século xx। - Cadernos de Cultura 23 (2009), pp. 44-52.

175 Pedro Salvado, "Amato Lusitano e outras presences médicas no espaço urbano albicastrense visibilidades e invisibilidades", Medicina na Beira Interior. Da Pré-História ao Século xxı - Cadernos de Cultura 23 (2009), pp. 69-82.

176 António Maria Romeiro Carvalho, "O número e a superstição em Amato Lusitano", Medicina na Beira Interior. Da Pré-História ao Século xxI - Cadernos de Cultura 24 (2010), pp. 36-39.

177 António Maria Martins Melo, "Amato Lusitano, leitor da Odisseia", Medicina na Beira Interior. Da Pré-História ao Século XXI — Cadernos de Cultura 27 (2013), pp. 27-30.

178 Maria do Sameiro BARRoso, "Amato Lusitano - os bezoares e a tradição das pedras curativas", Medicina na Beira Interior. Da Pré-História ao Século XxI — Cadernos de Cultura 24 (2010), pp. 41-46.

179 Ana Margarida BoRGES, "Anotações metalinguísticas nas obras de Amato e de Laguna: a metáfora terminológica", Medicina na Beira Interior. Da Pré-História ao Século xxI - Cadernos de Cultura 24 (2010), pp. 47-50.

180 Emília Oliveıra, "Da romã à nêspera: propriedades e fins terapêuticos de alguns frutos comuns em Portugal nas Enarrationes de Amato Lusitano", Medicina na Beira Interior. Da Pré-História ao Século xxI - Cadernos de Cultura 24 (2010), pp. 51-56.

181 Falecida em 2011. Ver Sociedade de Geografia de Lisboa. Relatório da Gerência e Parecer da Comissão Revisora de Contas. Referido a 31 de Dezembro de 2011. In: http://www.socgeografialisboa.pt/wp/ wp-content/uploads/2009/01/Relatorio-2011.pdf (consultado em 23/04/2014). 
Amato, sendo, igualmente dinamizadores importantes das Jornadas e dos Cadernos de Cultura. Nos últimos anos sublinhem-se os estudos de António Andrade integrados no projecto de investigação referido. Em 2011, ano de comemoração dos 500 anos de Amato Lusitano, os Cadernos de Cultura publicaram sobre Amato os seguintes estudos: António Andrade, De Antuérpia a Ferrara: o caminho de Amato Lusitano ${ }^{182}$; Alfredo Rasteiro, João Rodrigues Lusitano, Doutor Amado (1511-1568) e Armando Tavares de Sousa, estudioso de Amado ${ }^{183}$; João Maria Nabais, Amato e os médicos da diáspora: a face oculta das atribulaçóes dos judeus portugueses ${ }^{184}$; Emílio Rivas Calvo; Carlos d'Abreu, Amato Lusitano: na Universitatis Studii Salamantini ${ }^{185}$; Maria José Leal, Amato, Inédia e Chi Kung: quebrando o circuito da fome ${ }^{186}$; António Lourenço Marques, Amato Lusitano: o médico vai até ao fim ${ }^{187}$; Aires Gameiro, Amato Lusitano (1511-1568): identidade e cultura judaico-cristá europeia do século Xvi ${ }^{188}$. E em 2012 foram publicados textos que serviram de base a comunicações apresentadas aquando da sessão comemorativa do quinto centenário de Amato Lusitano: João Marinho dos Santos, A história de "Amato Lusitano" na história de Portugal ${ }^{189}$; Luís Nuno Ferraz de Oliveira, O meu Amato Lusitano ${ }^{190}$; António Manuel Lopes Andrade, Amato Lusitano em Ancona: a tragédia da família Pires ${ }^{191}$; João Manuel Nunes Torrão, Amato Lusitano: entre o Index Dioscoridis (1536) e as Enarrationes (1553) ${ }^{192}$; Carlos de Miguel Mora, Do Index às Enarrationes. Um esboço de estudo comparativo através de quatro

182 António Manuel Lopes ANDRADE, "De Antuérpia a Ferrara: o caminho de Amato Lusitano e da sua família", Medicina na Beira Interior. Da Pré-História ao séc. xxI - Cadernos de Cultura 25 (2011), pp. 5-16.

183 Alfredo RASTEIRo, "João Rodrigues Lusitano, Doutor Amado (1511-1568)". Medicina na Beira Interior. Da Pré-História ao séc. XXI - Cadernos de Cultura 25 (2011), pp. 17-20; "Armando Tavares de Sousa, estudioso de Amado. In Memoriam". Medicina na Beira Interior. Da Pré-História ao séc. xxI - Cadernos de Cultura 25 (2011), pp. 47-48.

184 João Maria Nabals, "Amato e os médicos da diáspora: a face oculta das atribulações dos judeus portugueses". Medicina na Beira Interior. Da Pré-História ao séc. XXI - Cadernos de Cultura 25 (2011), pp. 21-30.

185 Emílio Rivascalvo; Carlos d'Abreu, "Amato Lusitano: na Universitatis Studii Salamantini". Medicina na Beira Interior. Da Pré-História ao séc. XxI - Cadernos de Cultura 25 (2011), pp. 31-36.

186 Maria José LeAL, "Amato, Inédia e Chi Kung: quebrando o circuito da fome". Medicina na Beira Interior. Da Pré-História ao séc. XXI - Cadernos de Cultura 25 (2011), pp. 37-40.

187 António Lourenço Maroues, "Amato Lusitano: o médico vai até ao fim". Medicina na Beira Interior. Da Pré-História ao séc. XXI - Cadernos de Cultura 25 (2011), pp. 41-44.

188 Aires GameIRo, "Amato Lusitano (1511-1568): identidade e cultura judaico-cristã europeia do século xvI". Medicina na Beira Interior. Da Pré-História ao séc. XXI - Cadernos de Cultura 25 (2011), pp. 45-46.

189 João Marinho dos SANTOS, A história de "Amato Lusitano" na história de Portugal, Medicina na Beira Interior. Da Pré-História ao séc. XXI - Cadernos de Cultura 26 (2012), pp. 8-13.

190 Luís Nuno Ferraz de OliveIRA, "O meu Amato Lusitano", Medicina na Beira Interior. Da Pré-História ao séc. XXI - Cadernos de Cultura 26 (2012), pp. 14-19.

191 António Manuel Lopes ANDRADE, "Amato Lusitano em Ancona: a tragédia da família Pires", Medicina na Beira Interior. Da Pré-História ao séc. XxI - Cadernos de Cultura 26 (2012), pp. 20-27.

192 João Manuel Nunes TorRÃo, "Amato Lusitano: entre o Index Dioscoridis (1536) e as Enarrationes (1553)", Medicina na Beira Interior. Da Pré-História ao séc. XXI - Cadernos de Cultura 26 (2012), pp. 28-30. 
entradas ${ }^{193}$; Alfredo Rasteiro, João Rodrigues Lusitano - Doutor Amado - serviu as Musas: amou a Poesia, cultivou a Ciência ${ }^{194}$; J. A. David de Morais, As Parasitoses nas "Centúrias" de Amato Lusitano ${ }^{195}$; António Lourenço Marques, O ser humano na clínica de Amato Lusitano - rumo ao conceito de dignidade ${ }^{196}$; Maria Adelaide Neto Salvado, Amato num mito e um mito em Amato ${ }^{197}$; Joaquim Candeias da Silva, João Rodrigues... Amado, Lusitano, de Castelo Branco (1511-1568): Contributo para uma aclaração dos seus elos familiares ${ }^{198}$; Maria José Leal, No Cenotáfio de Amato ${ }^{199}$; Virgínia Soares Pereira, Amato Lusitano: a propósito de uma breve nota resendiana ${ }^{200}$; António Maria Martins Melo, Janela de aromas: excertos do Index de Amato Lusitano ${ }^{201}$; Maria do Sameiro Barroso, As filhas de Pirra em Amato Lusitano, um caso de embriotomia (VI Centúria, Cura LI) 202; Gabriela Valadas e Daniel Cartucho, Tumor da mama em Amato Lusitano - da semiologia à terapêutica ${ }^{203}$; Isilda Teixeira Rodrigues, Alguns factores que contribuíram para o desenvolvimento da Medicina de Amato Lusitano ${ }^{204}$; Albano Mendes de Matos, A atitude Cientifica em Amato Lusitano ${ }^{205}$; Lurdes Cardoso, Amato Lusitano e alguns dos seus contemporâneos ${ }^{206}$;

193 Carlos de Miguel Mora, "Do Index às Enarrationes. Um esboço de estudo comparativo através de quatro entradas", Medicina na Beira Interior. Da Pré-História ao séc. XxI - Cadernos de Cultura 26 (2012), pp. 31-36.

194 Alfredo RASTEIRO, "João Rodrigues Lusitano - Doutor Amado - serviu as Musas: amou a Poesia, cultivou a Ciência", Medicina na Beira Interior. Da Pré-História ao séc. XXI - Cadernos de Cultura 26 (2012), pp. 37-44.

195 J. A. David de Morals, "As Parasitoses nas "Centúrias" de Amato Lusitano", Medicina na Beira Interior. Da Pré-História ao séc. XXI - Cadernos de Cultura 26 (2012), pp. 45-54.

196 António Lourenço MARoues, "O ser humano na clínica de Amato Lusitano - rumo ao conceito de dignidade", Medicina na Beira Interior. Da Pré-História ao séc. xxI - Cadernos de Cultura 26 (2012), pp. 55-60.

197 Maria Adelaide Neto Salvado, "Amato num mito e um mito em Amato", Medicina na Beira Interior. Da Pré-História ao séc. XXI - Cadernos de Cultura 26 (2012), pp. 61-66.

198 Joaquim Candeias da SILVA, "João Rodrigues... Amado, Lusitano, de Castelo Branco (1511-1568): Contributo para uma aclaração dos seus elos familiares", Medicina na Beira Interior. Da Pré-História ao séc. xxI - Cadernos de Cultura 26 (2012), pp. 67-73.

199 Maria José LeAL, "No Cenotáfio de Amato", Medicina na Beira Interior. Da Pré-História ao séc. xxI Cadernos de Cultura 26 (2012), pp. 74-77.

200 Virgínia Soares Pereira, "Amato Lusitano: a propósito de uma breve nota resendiana", Medicina na Beira Interior. Da Pré-História ao séc. xxI - Cadernos de Cultura 26 (2012), pp. 78-80.

201 António Maria Martins Melo, "Janela de aromas: excertos do Index de Amato Lusitano", Medicina na Beira Interior. Da Pré-História ao séc. xx। - Cadernos de Cultura 26 (2012), pp. 81-87.

202 Maria do Sameiro BARroso, "As filhas de Pirra em Amato Lusitano, um caso de embriotomia (VI Centúria, Cura LI)", Medicina na Beira Interior. Da Pré-História ao séc. XXI - Cadernos de Cultura 26 (2012), pp. 88-93.

203 Gabriela VAladAs; Daniel CARTUCho, "Tumor da mama em Amato Lusitano - da semiologia à terapêutica", Medicina na Beira Interior. Da Pré-História ao séc. XxI - Cadernos de Cultura 26 (2012), pp. 94-97.

204 Isilda Teixeira RodRIGUes, "Alguns factores que contribuíram para o desenvolvimento da Medicina de Amato Lusitano", Medicina na Beira Interior. Da Pré-História ao séc. xxI - Cadernos de Cultura 26 (2012), pp. 98-100.

205 Albano Mendes de Matos, "A atitude Científica em Amato Lusitano", Medicina na Beira Interior. Da Pré-História ao séc. XXI - Cadernos de Cultura 26 (2012), pp. 101-104.

206 Lurdes CARDoso, "Amato Lusitano e alguns dos seus contemporâneos", Medicina na Beira Interior. 
Aires Gameiro, Amato Lusitano, homo europeus: Expoente Cimeiro da Cultura Europeia JudaicoCristã no século Xvi ${ }^{207}$; João Maria Nabais, O Judaísmo Humanista em Amato Lusitano ${ }^{208}$; Maria Antonieta Garcia, Cinco médicos Beirões e a conversão forçada ${ }^{209}$. Na mesma revista de 2012 assinale-se nas últimas páginas a informação diversificada das actividades realizadas aquando das comemoraçôes do V Centenário do Nascimento de Amato Lusitano ${ }^{210}$.

\section{AUTORES ESTRANGEIROS ESTUDIOSOS DE AMATO QUUE PUBLICARAM EM PORTUGAL}

Vários autores estrangeiros publicaram sobre Amato Lusitano, designadamente em Portugal. Com frequência aborda-se a presença de Amato em Itália ou no extremo da Europa. É o caso de Jacob Seide ${ }^{211}$, J. Nehama $(1955)^{212}$, Hirsh Rudy (1955) ${ }^{213}$, Harry Friedenwald

Da Pré-História ao séc. xxI - Cadernos de Cultura 26 (2012), pp. 105-108.

207 Aires GameIro, "Amato Lusitano, homo europeus: Expoente Cimeiro da Cultura Europeia Judaico-Cristã no século xvı", Medicina na Beira Interior. Da Pré-História ao séc. xxı - Cadernos de Cultura 26 (2012), pp. 109-112.

208 João Maria Nabals, "O Judaísmo Humanista em Amato Lusitano", Medicina na Beira Interior. Da Pré-História ao séc. XxI - Cadernos de Cultura 26 (2012), pp. 113-117.

209 Maria Antonieta GARCiA, "Cinco médicos Beirões e a conversão forçada", Medicina na Beira Interior. Da Pré-História ao séc. xxI - Cadernos de Cultura 26 (2012), pp. 118-128.

210 Sublinhe-se, entre vários, além dos discursos oficiais introduzidos na revista, do Presidente da República e do Presidente da Câmara de Castelo Branco, as actividades desenvolvidas em 2011, homenagem aos estudiosos de Amato e algumas edições realizadas como: Amato Lusitano Judeu Errante, de Armando Moreno (Peça vicentina em 3 actos - Comemorações dos 500 anos do nascimento de Amato Lusitano, Prémio Marcelino Mesquita); Amato Lusitano e as Rosas, textos de Maria Adelaide Neto Salvado, Edição da Câmara Municipal de Castelo Branco; O Corpo do Coração - Horizontes de Amato Lusitano - catálogo da Exposição - Pedro Salvado, Edição da Câmara Municipal Castelo Branco; Amato Lusitano Cidadão de Castelo Branco, de José Lopes Dias - Reedição da Câmara Municipal Castelo Branco; Amato Lusitano nos Caminhos do Mundo - O Saber sem Fronteiras - Caderno Especial do Jornal do Fundão de 10/11/2011; Catálogo da inauguração da estátua Diáspora, Edição da Câmara Municipal Castelo Branco; Amado Amato - antologia de poesia dedicada a Amato Lusitano, organizada por Maria de Lurdes Barata e Pedro Salvado, Edição da Câmara Municipal Castelo Branco; Jardim Amato Lusitano, de Maria Adelaide Salvado e Maria de Lurdes Cardoso, Edição da Câmara Municipal Castelo Branco; Ode a Amato Lusitano, da autoria de António Salvado, Edição da Câmara Municipal Castelo Branco.

211 Cf. Jacob SEIDE, "The two diabetics of Amatus Lusitanus", Imprensa Médica 19.11 (1955), pp. 670-674.

212 Cf. J. Nehama, "Amato Lusitano à Salonique", in Homenagem ao Doutor João Rodrigues de Castelo Branco (Amato Lusitano). Castelo Branco, Câmara Municipal de Castelo Branco, 1955, pp. 213-214.

213 Cf. Hirsch Rudy, "Amatus Lusitanus (Biographischer Rahmen)", in Homenagem ao Doutor João Rodrigues de Castelo Branco (Amato Lusitano). Castelo Branco, Câmara Municipal de Castelo Branco, 1955. pp. 193-211. 
$(1955)^{214}$, Lavoslav Glesinger (Estudos de Castelo Branco, 1968) ${ }^{215}$, Joshua O. Leibowitz (Estudos de Castelo Branco, 1961, 1968) ${ }^{216}$, Ivolino de Vasconcelos ${ }^{217}$, Marija Ana Dürrigl, Stella Fatovic Ferencic (Acta Médica Portuguesa, 2002) ${ }^{218}$, Alfredo Pérez Alencart (Medicina na Beira Interior. Da Pré-História ao Século XxI - Cadernos de Cultura $)^{219}$

214 Harry FriedenwALD, "Medical works of Amatus Lusitanus". Homenagem ao Doutor João Rodrigues de Castelo Branco (Amato Lusitano). Castelo Branco, Câmara Municipal de Castelo Branco, 1955, pp. 177-191.

215 Cf. Lavoslav Glesinger, "Amatus Lusitanus à Raguse" in Centenário (IV) de João Rodrigues de Castelo Branco - Amato Lusitano, Castelo Branco, Estudos de Castelo Branco, 1968, pp. 111-131; Amato Lusitano em Ragusa. Estudos de Castelo Branco 28 (1968), pp. 170-178.

216 Cf. Joshua O. LeIBowitz, "Amatus Lusitanus on sudden death due to 'Obstruction in the heart'" (1560), Estudos de Castelo Branco, 4 (1961) pp. 11-26; "Simpósio de Amato Lusitano em Sena. Amatus Lusitanus à Salonique" in Centenário (IV) de João Rodrigues de Castelo Branco - Amato Lusitano. Castelo Branco, Estudos de Castelo Branco, 1968, pp. 41-46; "Amatus Lusitanus (1511-1568) à Salonique", Estudos de Castelo Branco 28 (1968) pp. 90-93; "Amato Lusitano (1511-1568) em Salónica", Estudos de Castelo Branco 28 (1968) pp. 93-95.

217 Cf. Ivolino de Vasconcelos, "Discurso de encerramento de 'Simpósio de Amato Lusitano', em Siena, do Prof. (...)" in Centenário (IV) de João Rodrigues de Castelo Branco - Amato Lusitano. Castelo Branco, Estudos de Castelo Branco, 1968, pp. 191-192; Discurso de encerramento do "Simpósio de Amato Lusitano" em Siena. Estudos de Castelo Branco 29 (1969), pp. 21-22.

218 Cf. Marija-Ana Dürrigl; Stella Fatovic-Ferentic, "The medical practice of Amatus Lusitanus in Dubrovnik (1556-1558) a short reminder on the $445^{\text {th }}$ anniversary of his arrival", Acta Médica Portuguesa 15.1(2002), pp. 37-40.

219 Alfredo Pérez Alencart, "Descubrimiento de Amato Lusitano", Medicina na Beira Interior. Da Pré-História ao Século xxI - Cadernos de Cultura 19 (2005) pp. 40-41. 


\section{CONCLUSÃO}

Pelo que fica exposto, Amato Lusitano, figura maior da história da medicina portuguesa é, igualmente, uma referência na história da medicina internacional. Apesar de muitos estudos publicados sobre a sua vida e a sua obra, de dimensôes, âmbitos e profundidades diferentes, sendo uma boa parte muito recente, Amato Lusitano continua a aguardar um trabalho historiográfico de grande fôlego, segundo os mais recentes e autorizados métodos da história cultural da ciência e da medicina e que seja marcante para a historiografia médica, sobretudo um trabalho de natureza biográfica. Os trabalhos sobre Amato sublinham igualmente a possibilidade de trabalhos multifacetados que sobre Amato se podem realizar e que o tornam numa fonte de investigação de enorme fecundidade. O quinto centenário de Amato proporcionou diversas iniciativas e produçóes científicas. As diferentes actividades levadas a bom porto em Castelo Branco, na Biblioteca Nacional de Portugal, bem como o projecto de investigação Dioscórides e o Humanismo Português: os Comentários de Amato Lusitano do qual decorre a presente publicação testemunham o excelente trabalho realizado nos últimos anos sobre Amato Lusitano. 
A partir dos alvores do século XVI, a matéria médica torna-se indiscutivelmente um tema de primeira grandeza entre os membros da República das Letras, objecto de estudo e de controvérsia entre os mais notáveis humanistas europeus, em particular entre os cultores da arte médica. Entre os autores em destaque neste volume encontram-se, à cabeça, os nomes de Amato Lusitano, Garcia de Orta e Nicolás Monardes, famosos pelos contributos valiosos que deram para o conhecimento do mundo natural. 0 volume encontra-se dividido em duas partes: a primeira, subordinada ao título "Humanismo e Ciência", alberga os estudos que versam sobre todos os autores estudados, à excepção de Amato Lusitano; a segunda está reservada a um conjunto de trabalhos dedicados exclusivamente ao médico albicastrense, cuja autoria se fica a dever, em boa parte, aos membros da equipa do projecto de I\&D "Dioscórides e o Humanismo Português: os Comentários de Amato Lusitano", tomando, por isso, 0 seu próprio título. Nesta segunda parte, oferece-se, desde já, aos leitores uma amostra significativa do trabalho desenvolvido no âmbito do projecto e que culminará, assim se espera, na edição e tradução integral para língua portuguesa das quatro obras previstas de Dioscórides, Amato Lusitano e Pietro Andrea Mattioli. 
